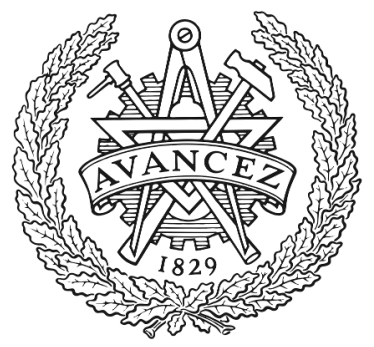

CHALMERS

UNIVERSITY OF TECHNOLOGY

\title{
Numerical modelling of neutral atmospheric boundary layer flow through heterogeneous forest canopies in complex terrain (a case study of a Swedish
}

Downloaded from: https://research.chalmers.se, 2023-04-26 09:52 UTC

Citation for the original published paper (version of record):

Abedi, H., Sarkar, S., Johansson, H. (2021). Numerical modelling of neutral atmospheric boundary layer flow through heterogeneous forest

canopies in complex terrain (a case study of a Swedish wind farm). Renewable Energy, 180: 806-828. http://dx.doi.org/10.1016/j.renene.2021.08.036

N.B. When citing this work, cite the original published paper. 


\title{
Numerical modelling of neutral atmospheric boundary layer flow through heterogeneous forest canopies in complex terrain (a case study of a Swedish wind farm)
}

\author{
Hamidreza Abedi a, c, *, Saptarshi Sarkar ${ }^{\text {b, c, }}$, Håkan Johansson b,c \\ ${ }^{a}$ Division of Fluid Dynamics, Department of Mechanics and Maritime Sciences, Chalmers University of Technology, SE-412 96, Gothenburg, Sweden \\ ${ }^{\mathrm{b}}$ Division of Dynamics, Department of Mechanics and Maritime Sciences, Chalmers University of Technology, SE-412 96, Gothenburg, Sweden \\ ' Swedish Wind Power Technology Centre (SWPTC), SE-412 96, Gothenburg, Sweden
}

\section{A R T I C L E I N F O}

\section{Article history:}

Received 9 June 2021

Received in revised form

9 August 2021

Accepted 11 August 2021

Available online 18 August 2021

\section{Keywords:}

Complex terrain

Large-eddy simulation

Atmospheric boundary layer flow

Heterogeneous forest

Short-term damage equivalent load

Bearing life

\begin{abstract}
A B S T R A C T
This paper exposes the risk of generalization of wind conditions from a single met-mast measurement to be representative of the actual flow field in a wind farm situated in complex terrain. As a case study, Large-Eddy Simulation (LES) of the neutral Atmospheric Boundary Layer (ABL) flow for a mid-western Sweden wind farm is performed. The site-specific complex topography and the forest properties like the Plant Area Density and the tree heights are extracted from the Airborne Laser Scanning (ALS) 3D data, thus the forest is heterogeneous. To emphasize the impact of the local topography and surface roughness on the wind field, the wind turbines are not included in the numerical simulations. The predicted wind speeds using LES are compared to wind speed from the nacelle-mounted anemometers taken from the wind farm's turbine SCADA data, focusing on the wake-free turbines. A sufficient degree of match is observed, supporting the accuracy of the numerical simulations. The results show that inflow variables i.e., mean wind speed, shear exponent and turbulence intensity vary at each wind turbine location justifying the need for turbine-specific assessment of the wind resource in a wind farm located in forested complex terrain. The inter-turbine (between turbines in the wind farm) differences in wind resource is quantified in terms of the difference in turbine-specific structural and mechanical loads by running wind turbine mechanical simulations using the extracting the wind fields predicted by the LES. The results show that not only inter-turbine loads varying significantly in the wind farm, but the turbine loads also differ significantly if a homogeneous assumption is made for the forest. Most importantly, it was found that the homogeneous forest assumption predicted a higher turbulence intensity compared to a heterogeneous forest resulting.
\end{abstract}

(C) 2021 Elsevier Ltd. All rights reserved.

\section{Introduction}

Wind power is known as one of the most environment-friendly sources of renewable and clean energy which has been a pioneering renewable technology in recent decades. The development and operation of wind farms requires wind resource assessment which is the core concept of the economic feasibility of a wind turbine farm project. Wind turbines always operate within the Atmospheric Boundary Layer (ABL) and are subjected to atmospheric

\footnotetext{
* Corresponding author. Division of Fluid Dynamics, Department of Mechanics and Maritime Sciences, Chalmers University of Technology, SE-412 96, Gothenburg, Sweden.

E-mail address: abedih@chalmers.se (H. Abedi).
}

turbulence [1,2]. Therefore, the prediction of the flow field is extremely important to ensure proper choice of turbine and operation, to reduce maintenance costs and increase turbine's life.

The Atmospheric Boundary Layer (ABL) flow consists of various spatial scales ranging from millimeters to several hundred meters determining the flow pattern over the entire wind farm. In ABL modeling, among various number of meteorological phenomena such as Coriolis force, buoyancy forces and heat transport, the impact of ground topography is taken into account as surface roughness, dominating the near-surface wind flow. The ground topography is mainly characterised by the complex terrain [3] and the vegetation [4]. The complex terrain affects the motion of largescale turbulent structures [5] whereas the motion of small-scale turbulent structures is governed by the vegetation. Therefore, the 
airflow in a wind farm strongly depends on local topography and surface roughness [6]. The local topography and surface roughness significantly change the flow patterns in and around wind farms which in turn increase the uncertainty of on-site wind resource assessment. Moreover, the flow features significantly affect the aerodynamic loads on rotor blades and annual power production for a wind farm located in a complex terrain.

Because of the great inhomogeneity of the flow features in a complex terrain, the on-site measurement [7] cannot afford a full map of the wind field over the entire wind farm. In addition, the uncertainty of local field measurement to provide a detailed description of a wind resource due to the topographic complexity [8] along with the time-consuming and expensive process of collecting measured data by means of on-site meteorological masts motivates performing numerical modelling to predict the wind field over any complex terrain wind farm [9]. Therefore, developing accurate computational models [10] for the flow field for wind farms located in hilly regions is quite important for design purposes.

Historically, the ABL modelling over complex terrain (mainly 2D/3D low hill) was performed using analytical theory [11-13] showing a reliable flow prediction approach in the region without separation. Advances in computational power and development of numerical algorithms for non-linear equations enabled to simulate ABL using Computational Fluid Dynamics (CFD). Nowadays, CFD has become a common numerical simulation tool to predict the atmospheric boundary layer turbulence structure ranging from mesoscale to microscale modeling. Apart from successfully usage of mesoscale models [14] for wind resource mapping of countries and regions with a typical model grid resolution of $1-5 \mathrm{~km}$, the limitations of mesoscale models (due to a very coarse horizontal resolution and resolved time scales) make them improper tools for wind farm and wind turbine design. This propels the use microscale models for micro-siting even though they most often rely on local measurements. In microscale models, CFD can cover 10-20 km area and is run with 2-20 m model grid resolution which makes it possible to capture topographic effects of complex terrains and vegetation. Hence, the capability of advanced CFD of including topographical phenomena in ABL simulation flow provides a more realistic wind farm flow prediction. However, it requires large computational resources for wind resource assessment over a complex terrain. Moreover, the predicted wind farm flow by CFD is highly affected by the computational grid resolution, the specified boundary conditions, the heterogeneous surface roughness and the choice of turbulence models.

Two common CFD methodologies which have been extensively used to simulate the atmospheric boundary layer flow are the Reynolds-Averaged Navier-Stokes (RANS) and Large-Eddy Simulation (LES). The RANS models only predict the mean flow where Reynolds stresses are entirely modeled using different turbulence closures with reasonable computational costs. They include constant numbers which are calibrated by either fundamental flows (e.g., channel flow) or measurement data which in turn increase uncertainties of RANS simulations. Moreover, at very highReynolds number turbulent flow such as ABL flow over the complex terrain including non-equilibrium region such as adverse pressure gradients [15] and three dimensional separation [16], the reliability and accuracy of RANS models to predict turbulence characteristics is low. On the other hand, LES is able to predict unsteady flow features and chaotic motion of turbulent structures at very high-Reynolds number flows where the large-scale flow structures are dominant. Unlike RANS, in LES the large flow structures, the so-called grid-scales, are resolved whereas the small flow structures, the so-called subgrid-scales, are modeled using a subgrid model [17]. Therefore, it can provide more accurate flow field than RANS. However, LES is a computationally expensive and requires more attention in the near wall region for flows with very high-Reynolds number such as ABL flow [18] to avoid mismatching between the modeled near-wall region and the resolved outer region.

Initial attempts for CFD modelling of the air flow over complex topographies were limited to the flat terrain and 2D/3D hills [19-23] and have been continuously developed until now [24-27]. A review of wind flow over hills, escarpments and valleys using RANS has been summarized by Bitsuamlak [28].

In 2000s, several studies have been carried out to simulate airflow over complex terrains [29-31] using RANS turbulence models [32-39]. In addition, the field measurement campaigns of two isolated hills, Askervein [40] and Bolund [41,42] have been widely used for validation of complex terrain flow models using steady-state RANS equations with $\mathrm{k}-\varepsilon$ and $\mathrm{k}-\omega$ turbulence closures [43-48].

In complex terrain, the highly variable ground elevations increase the complexity of the air flow. Furthermore, the wake interactions between the turbines and the local ground topography make the flow complexity greater so that the attached boundary layer flow assumption is no longer valid. The separated flow and recirculation regions increase the unsteadiness of the airflow and the RANS-based turbulence models are no longer capable of predicting the flow accurately. Hence, for a very high-Reynolds-number turbulent boundary layer such as ABL flow, the LES based turbulence model is a promising approach to simulate the air flow over complex terrains.

Successful applications of LES in ABL flow have been reported for simulating the flow over flat terrain [49-59]. Breton et al. [60] reviewed the current state-of-the-art Large-Eddy Simulation (LES) approach for wind farm aerodynamics under various atmospheric and terrain conditions. Similar to the RANS turbulence models, various studies have been performed to validate LES turbulence model against the field measurement over the Askervein hill [61-64] and Bolund hill [65-71]. In addition to the Askervein and Bolund as isolated hills, there are few studies on ABL flow over naturally complex terrain [72-80].

Like terrain complexity, the vegetation as a part of ground topography also has a significant impact on ABL flow. Apart from the practical risks associated with wind turbines in forest regions [81], a higher turbulence level and wind shear due to the forest canopies have been reported in various numerical and experimental studies [36,76,82-84]. In the past twenty years, successful numerical modellings of flow over and inside horizontally homogeneous forest canopies using LES have been performed [58,76-78,80,85-90]. Horizontally homogeneous forest canopies are presented by either Leaf Area Density (LAD) or Plant Area Density (PAD) varying in the vertical direction and considered as drag in the ABL flow. Leaf Area Density (LAD) or Plant Area Density (PAD) have been previously been used to quantify air-vegetation exchange of momentum, latent/sensible heat and carbon dioxide [91]. They are defined as one-sided plant/leaf area per unit of horizontal layer volume [92]. The difference between the PAD and LAD is that the PAD includes both leaf and wood surface areas whereas the LAD only includes leaf surface area. The distribution of plant/leaf elements from ground to top of canopy is defined by a vertical distribution profile of PAD/LAD. In addition, the Plant Area Index (PAI)/Leaf Area Index (LAI), obtained by the vertical integration of the PAD/LAD profiles, are dimensionless parameters that are usually used to characterize the density of canopies. The assumption of forest homogeneity increases the uncertainties of flow simulation where some of the extreme events such as wind gusts and sudden change in wind speed cannot be well-predicted. Therefore, inclusion of forest heterogeneity in numerical flow 
modelling provides more realistic simulation framework. However, obtaining accurate canopy properties is a difficult task [93]. Lately, Boudreault [94] and Arnqvist [91] presented numerical algorithms to extract the detailed distribution of Plant Area Density (PAD) profiles and Plant Area Index (PAI) from airborne laser (lidar) scan data for large areas with higher accuracy than the previous methods [95].

Contrary to the horizontally homogeneous forest, in heterogeneous forest, LAD/PAD profile varies in both horizontal and vertical directions. This inhomogeneity has a significant impact on the variability of wind field $[93,94,96]$ and it is more pronounced for wind farms located in a complex terrain. Recent studies by Boudreault et al. [96] and Ivanellet al. [39] have shown the importance of local heterogeneity of forest canopies in wind resource assessment where the forest edges and local variation of PAD distribution have large impacts on the airflow inside and above the canopies. Additionally, Ross [97] demonstrated that highly varying forest density results in acceleration and deceleration of the flow into and out of the canopy. However, to the best of authors' knowledge, there are very few studies comparing the flow field characteristics extracted from LES using heterogeneous forest assumption to operational or met mast data at several locations.

In this study, numerical simulation of the neutral ABL flow through heterogeneous and homogeneous forest canopies in complex terrain are performed. For homogeneous forest modeling, the average PAD profile over computational domain is used. The results for the neutral $A B L$ flow through homogeneous forest modeling are not presented and are used for comparison purposes only. The neutral ABL flow assumption helps to study the turbulence generation mechanism only by means of local topography and surface roughness [57] where the impact of the buoyancy forces are neglected. The focus of the study is to employ a highfidelity CFD method - the so-called Large-Eddy Simulation (LES) to model the airflow inside and over complex terrains and around each wind turbine in a mid-western Swedish wind farm while the difference between the heterogeneous and homogeneous forest assumptions on the dynamic response of the wind turbines in a wind farm is also investigated. A commercial software (STAR$\mathrm{CCM}+$ ) is used to predict the atmospheric turbulence and wind profile over the wind farm. The results are compared against the SCADA (Supervisory Control And Data Acquisition) data of the wind farm. To study and compare the impact of homogeneous and heterogeneous forest properties on the dynamic response of the wind turbines installed in the wind farm, the computed flow field by STAR-CCM + is supplied to the aeroelastic wind turbine simulator FAST [98]. FAST is an open-source CAE tool for predicting the power production and simulating the structural and system response of wind turbines developed by NREL.

\section{Complex topography}

The Röbergsfjället wind farm, located at Röbergskullen in southern part of Vansbro municipality in Sweden $\left(60^{\circ} 16^{\prime} 49.8^{\prime \prime} \mathrm{N}\right.$, $14^{\circ} 12^{\prime} 59.6^{\prime \prime} \mathrm{E}$ ), is used as the complex terrain where it is partly covered by heterogeneous forest with some clearings (see Fig. 1). The farm was built in 2007 with the highest point at $543 \mathrm{~m}$ above sea level (a.s.l) where the difference between the highest and lowest points of the wind farm is $\delta y_{g} \simeq 284 \mathrm{~m}$ (see Fig. 2). The wind farm consists of eight Vestas V90 horizontal axis wind turbines (referred to as WT1-WT8) with a hub height of $90 \mathrm{~m}$ and a rotor diameter of $90 \mathrm{~m}$, each with a capacity of $2 \mathrm{MW}$.

The complex topography of Röbergsfjället wind farm was extracted from Airborne Laser Scanning (ALS) 3D-data delivered on May 2017 by Swedish University of Agricultural Sciences, SLU (www.slu.se). The ALS data contains a point cloud with a point density $0.5-1$ points per square metre for the terrain and $1-2$ points per square metre for the vegetation (forest). A commercial software called Global Mapper was used to derive the complex terrain coordinates with the specified horizontal resolution of $7 \times 7$ $\mathrm{m}^{2}$. The coordinates were imported into STAR-CCM+ in the STL format to generate the computational grid for the numerical simulations.The forest properties, Plant Area Density (PAD) and trees height, have been extracted from the ALS data with the certain resolution of $20 \times 20 \mathrm{~m}^{2}$ and $2 \mathrm{~m}$ in the horizontal and vertical directions, respectively. The software to extract the forest properties from the ALS data is available at software repository GitHub [91,99].

Fig. 2 shows the terrain elevation with respect to sea level (left) and forest properties (right) in a local domain of $14 \times 16 \mathrm{~km}^{2}$ surrounding the wind farm. The red dots indicate the location of eight wind turbines of the wind farm where all are placed in the highest elevation of the neighbourhood region. Moreover, the black dot displays the location of the met mast.

\subsection{Measurement data}

The on-site meteorology mast data at Röbergsfjället site has been equipped with two heated cup and vane wind measurement stations designed for arctic conditions (Vaisala Wind Set WA25) at 40 and $60 \mathrm{~m}$ above ground. It determines the wind speed and direction as well as the shear exponent. It is located at the clearing region of the North of the wind farm, close to the wind turbine 1 (see Fig. 1 c). These data are used for validation of the numerical modelling. The measurement data include a full year mean and standard deviation of the wind speed measured in 2006 with the frequency of an hour.

According to Fig. 3, at $60 \mathrm{~m}$ above the ground the dominant wind direction is $216^{\circ}$ with respect to the North. The $10 \mathrm{~m} / \mathrm{s}$ mean wind speed, corresponding to the dominant wind direction, is chosen for the numerical simulation.Comparison between the fullday mean wind speed measurement with those measured only in the day-time and night-time can be observed in Fig. 4. The mean values for the full-day, day-time and night-time time intervals are approximately the same and they are equal to $6.8,6.6$ and $7.1 \mathrm{~m} / \mathrm{s}$, respectively. The small differences between these values are taken as support for adopting neutral atmospheric boundary layer flow assumption in this study.In addition, the turbulence intensity can be estimated from the measurement data. Fig. 5 shows the variation of the turbulence intensity with respect to the mean wind speed measured at the met mast point ( $60 \mathrm{~m}$ above ground) for 1-h averages over the year. As illustrated, the 0.9 quantile values of turbulence intensity for the measured data is below the class $\mathrm{C}$ of international standard IEC 61400-1 [100] for Normal Turbulence Model (NTM) wind condition. In other words, the turbulence intensity for turbine classification at the Röbergsfjället site is associated with the class $C$ of the IEC standard [100].

\section{Simulation set-up}

The numerical simulations are done over the complex terrains covered by the heterogeneous forest. For this purpose, a highfidelity CFD approach, Large-Eddy Simulation (LES) is employed over a rectangular computational domain to predict the neutral atmospheric turbulence and time-varying wind profile for a period of $90 \mathrm{~min}$ with output sampling of $10 \mathrm{~Hz}$. The computational domain has dimensions $9 \mathrm{Hx} 6 \mathrm{HxH}$ where $\mathrm{H}$ denotes the average height of $\mathrm{H} \simeq 1.0 \mathrm{~km}$ (app. four times higher than the difference between the highest and lowest points of the wind farm, i.e., $\delta y_{g} \simeq$ $284 \mathrm{~m}$ ) in the vertical direction ( $y$ ). In other words, LES simulations are performed over a rectangular box of size $L=9.0$ 


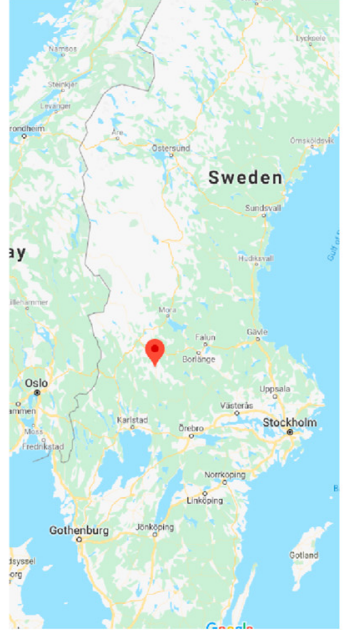

(a)

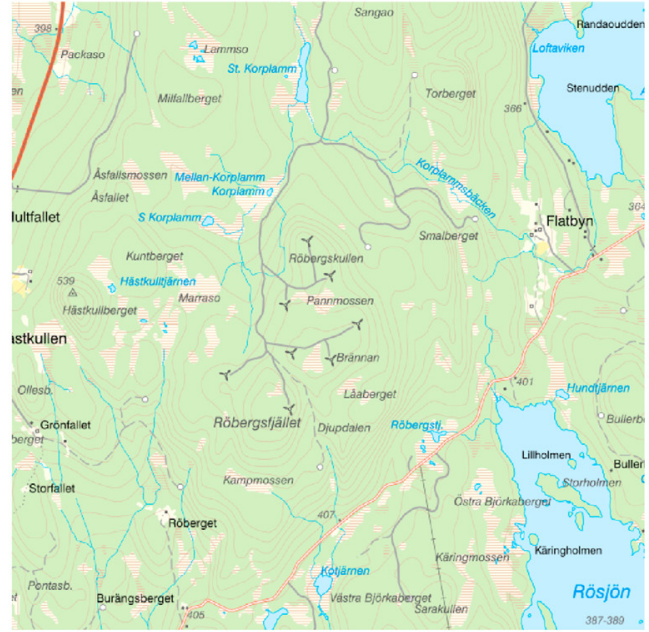

(b)

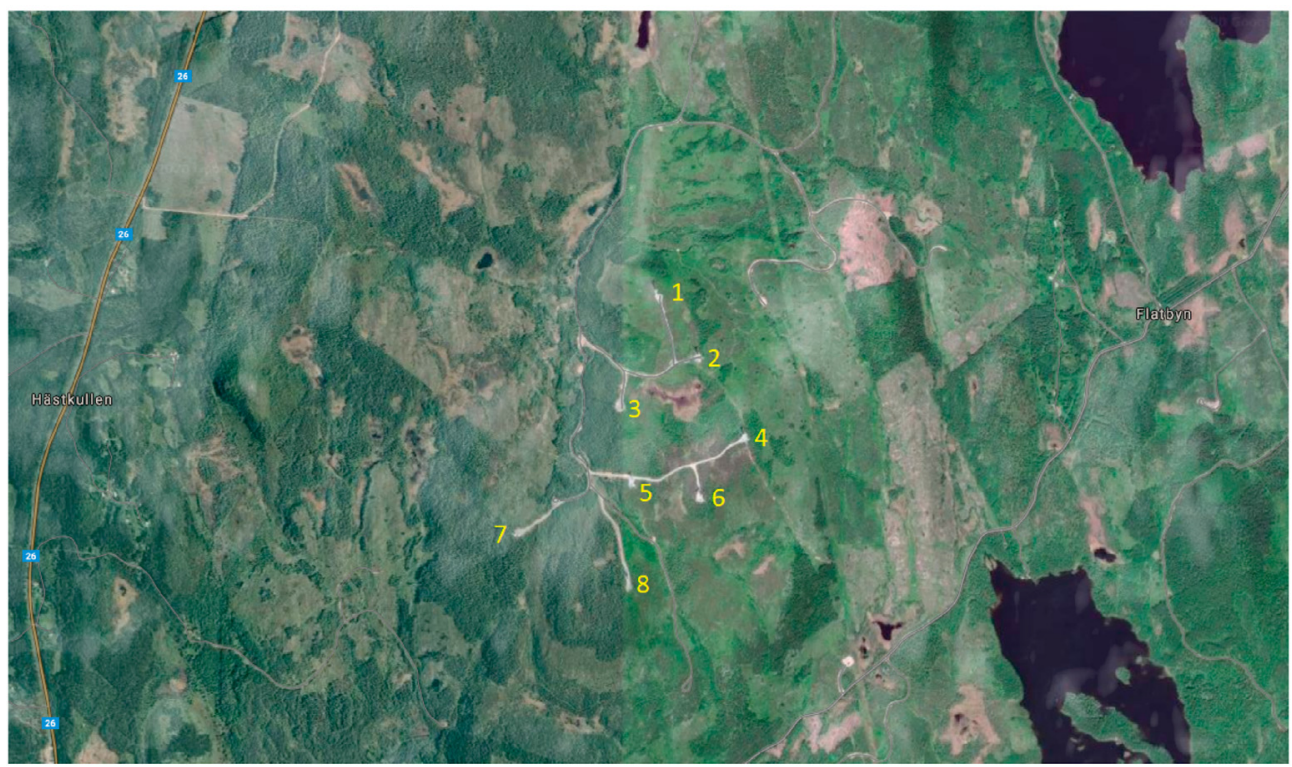

(c)

Fig. 1. The Röbergsfjället wind farm, located at Röbergskullen in southern part of Vansbro municipality, Sweden. The numbers indicate the location of eight wind turbines.

$\mathrm{km} \times \mathrm{W}=6.0 \mathrm{~km}$ in horizontal plane with average height of $\mathrm{H} \simeq 1.0 \mathrm{~km}$.

The size of the computational domain and simulation run-time are limited based on the available computational resources. Fig. 6 shows the layout of the computational grid and the location of the wind turbines inside the farm.As seen, the computational domain (enclosed by the black solid lines) has been chosen to be aligned with the dominant wind direction, $216^{\circ}$ w.r.t. to the North, at the site. The rotated domain has the advantage of perpendicular inflow at inlet boundary condition. Therefore, the length and width of the domain are associated with the local streamwise $(x)$ and spanwise $(z)$ directions, respectively. In addition, the wind farm is situated in the middle of the computational domain allowing turbulent structures to be developed within the distance between the inlet boundary and the wind farm. Because of the varying ground elevation in the computational domain, the maximum and minimum distance from the ground level are $1600 \mathrm{~m}$ and $900 \mathrm{~m}$, respectively. The minimum distance is equal to three times the difference between the highest and lowest points of the wind farm i.e., $300 \mathrm{~m}$. All sides of the computational domain are parallel to each other; and they are flat except the floor which is made up of the topography of the area extracted from the ALS data.

The computational grid spacing is constant in the horizontal directions with $\Delta x=\Delta z=17 \mathrm{~m}$ where $x$ and $z$ denote the local streamwise and spanwise directions, respectively. The extracted inhomogeneous PAD profiles over the wind farm, varying in both horizontal and vertical directions with a maximum trees height of $40 \mathrm{~m}$, is used to take the impact of vegetation on the airflow into account. In case of using the Monin-Obukhov similarity relationships with a prescribed physical roughness length [83], as recommended by Richards and Hoxey [101], the first cell height in the grid mesh must be at least ten times larger than the physical roughness length at the ground prescribed by $z_{0}=0.001 \mathrm{~h}$ where $\mathrm{h}$ is the canopy height [83]. In the heterogeneous forest, the physical roughness length varies spatially, so the first cell height can be specified based on the maximum trees height in the computational domain.

In STAR-CCM+, the LES solver can only handle the ground as the 


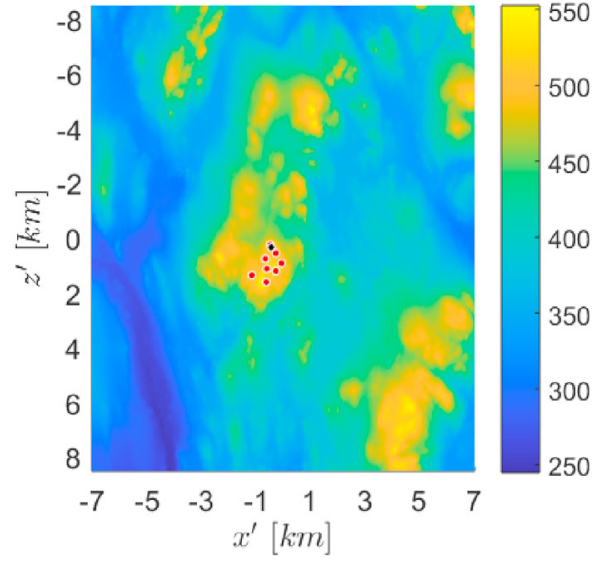

(a)

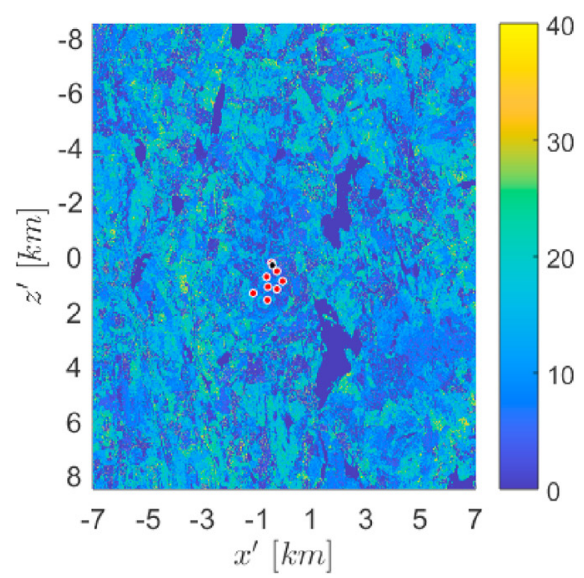

(b)

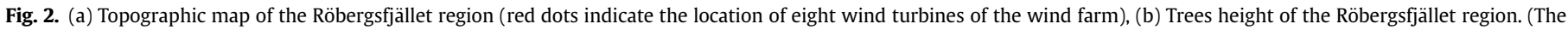
red dots and the black dot display the location of eight wind turbines and the met mast, respectively.).

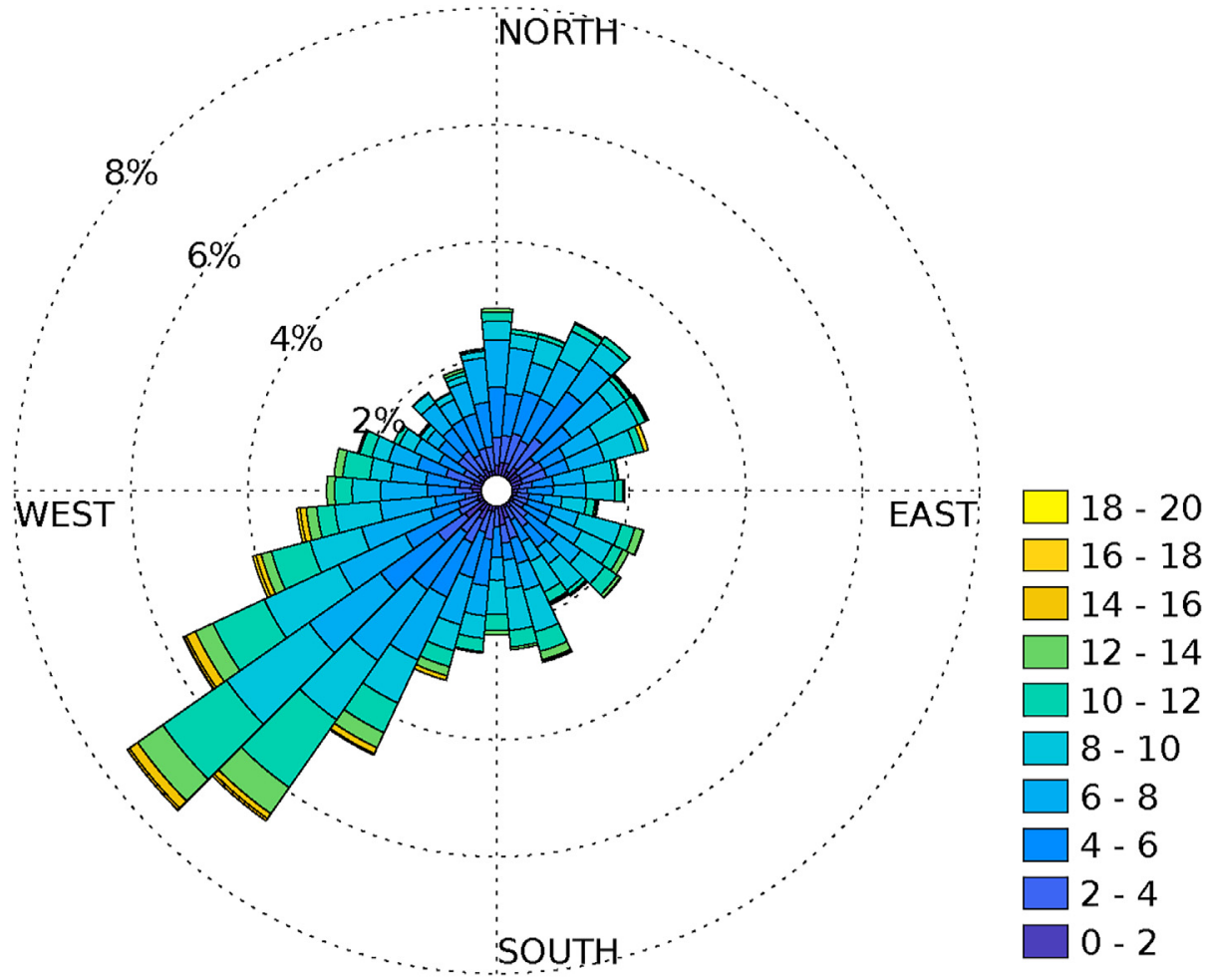

Fig. 3. Wind rose of the mean wind speed measurement in 2006 at $60 \mathrm{~m}$ above the ground for Röbergsfjället site.

smooth wall. To avoid increasing the number of grid cells and to maintain enough resolution near the wall for the ABL flow simulation, the first cell height is considered equal to $2 \mathrm{~m}$ while thirteen grid cells are used to discretize the highest canopy height in the vertical direction. In addition, thirty grid cells are vertically stretched until $210 \mathrm{~m}$ to refine the wall region. Above the height of $210 \mathrm{~m}$, a constant grid spacing of $\Delta y=17 \mathrm{~m}$ is used. Because of the complex topography over the entire domain, the number of grid cells in the vertical direction vary between 78 and 91 resulting in a total number of approximately 16 million grid cells for the entire computational domain.

\subsection{Forest properties}

Fig. 7 presents the distribution of trees height and Plant Area Index (PAI) within the local region and the computational domain. As stated in section 2, the forest properties were extracted from ALS data delivered on May 2017. They are almost identical where the average of the trees height are in the range of $10-20 \mathrm{~m}$ and the maximum of trees height is restricted to $40 \mathrm{~m}$. However, there are many scattered clearing zones in the local region violating the homogeneity assumption for the Röbergsfjället region.

In addition, the average value of the PAI distribution is about one (below the averaged PAI values for the coniferous and deciduous 


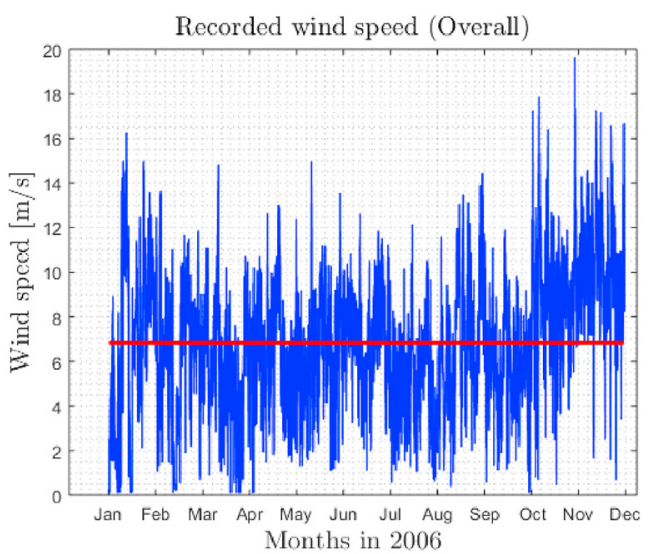

(a)

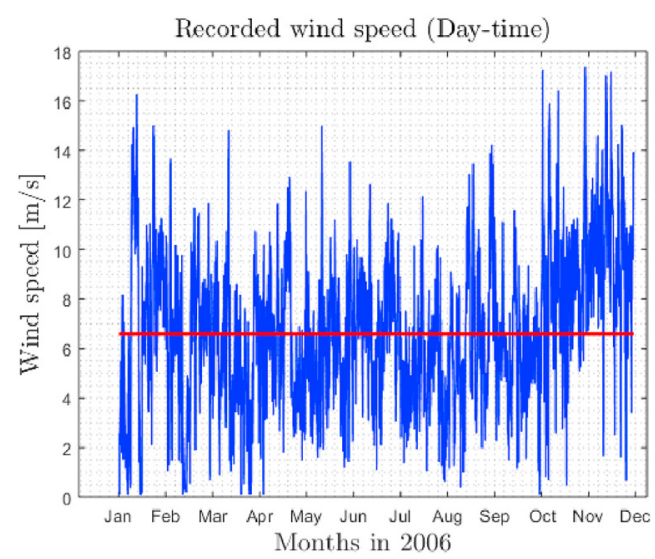

(b)

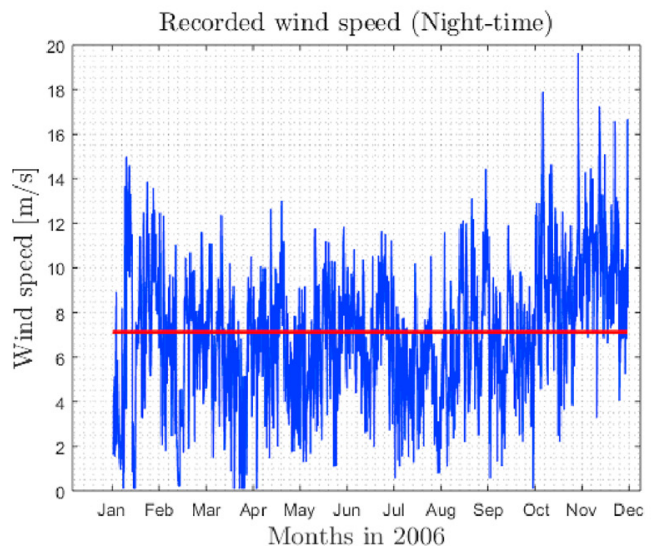

(c)

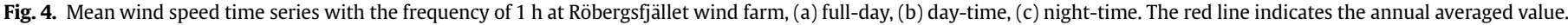

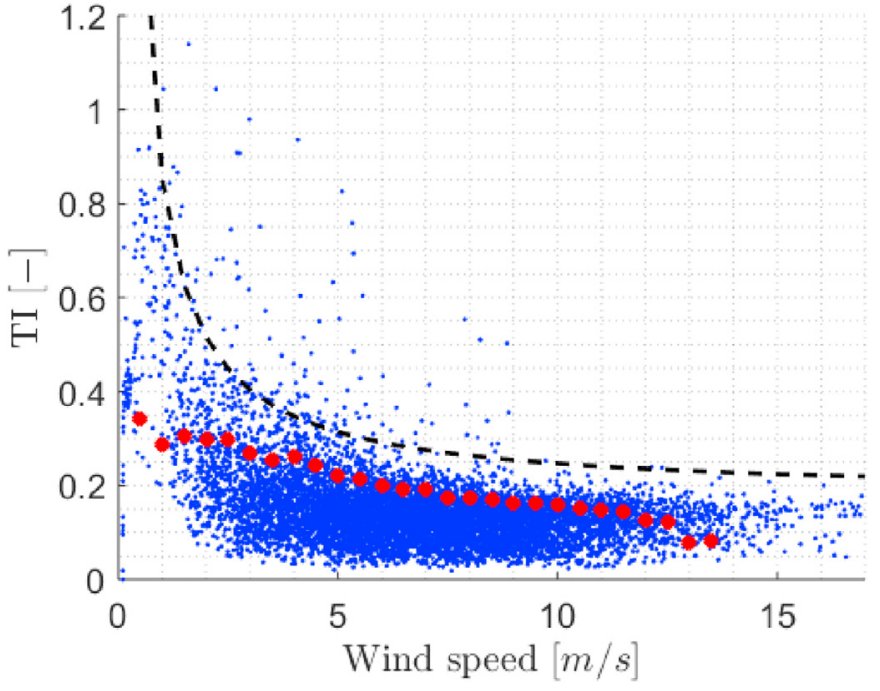

Fig. 5. Variation of turbulence intensity with the mean wind speed, Blue dots: the measurement data, Black dashed-line: IEC 61400-1, NTM- Class C, Red circles: $90 \%$ quantile of turbulence intensity for the given mean wind speed. forests in global temperate ecosystems [102]) which reveals that the wind farm is not been covered by a dense forest [86]. The average PAD profile can be also computed from the vertical distribution of PAD over the entire local and computational domains as presented in Fig. 8.

Both profiles are rather similar except for the first $2 \mathrm{~m}$ near the ground. The mean PAD profile of the computational domain (blue line in Fig. 8) is used for the precursor and homogeneous forest simulations.

\subsection{Governing equations}

In LES, the turbulent eddies are divided into large, resolvable scales and small, subgrid scales (SGS) where the small scales are modeled. The distinction between large and SGS scales is done implicitly by the grid, referred to the grid filtering. The incompressible, grid-filtered, Navier-Stokes equations are expressed as

$\frac{\partial \bar{v}_{i}}{\partial x_{i}}=0$ 


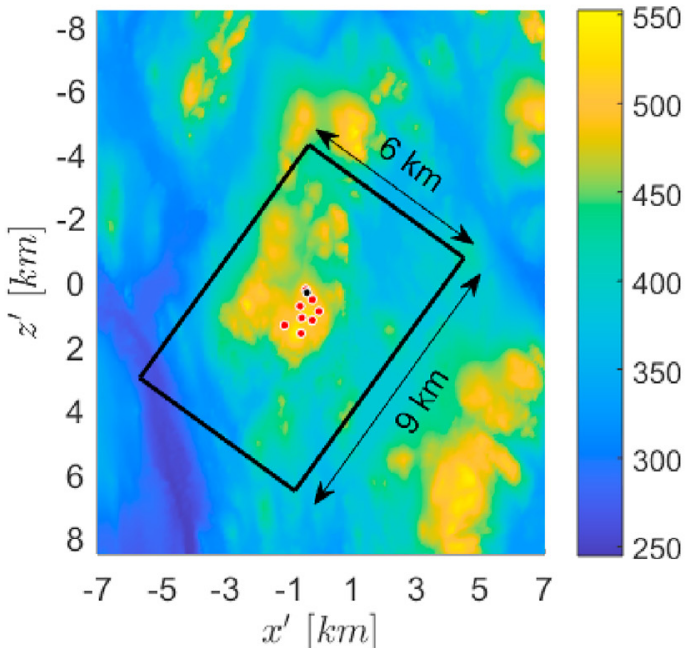

(a)

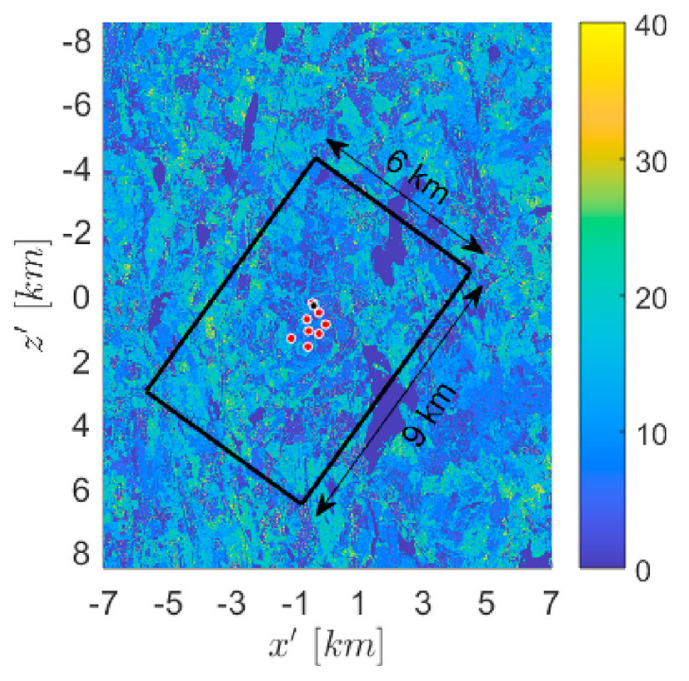

(b)

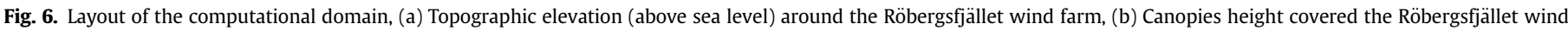
farm. (The red dots and the black dot indicate the location of eight wind turbines and the met mast, respectively in the wind farm.).

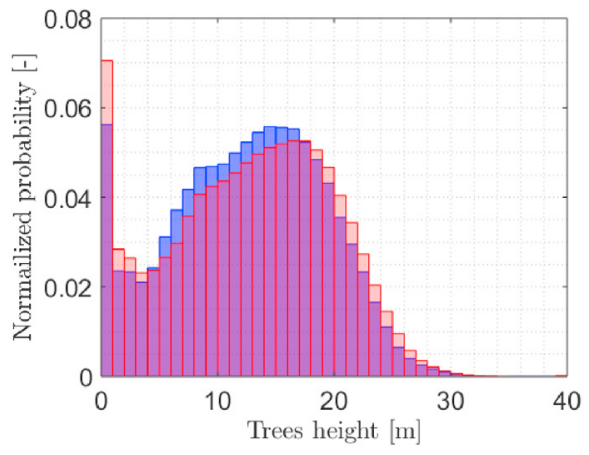

(a)

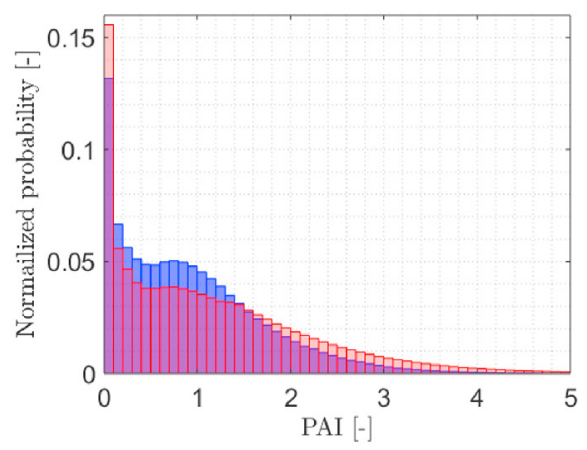

(b)

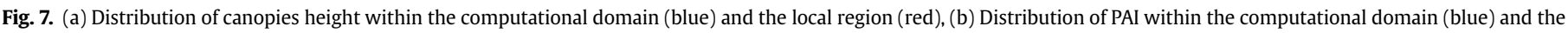
local region (red).

$\frac{\frac{\partial \bar{v}_{i}}{\partial t}+\partial\left(\bar{v}_{i} \bar{v}_{j}\right)}{\partial x_{j}=-\frac{1}{\rho} \frac{\partial \bar{p}}{\partial x_{i}}+\frac{\partial}{\partial x_{j}}\left(\nu \frac{\partial \bar{v}_{i}}{\partial x_{j}}-\tau_{i j}\right)+F_{f, i}}$

where $\bar{v}_{i}, \rho, \bar{p}$ and $\nu$ denote the velocity component in the $x_{i}$-direction $\left(x_{i}=\{x, y, z\}\right)$, the air density, the pressure and the kinematic viscosity, respectively and the overbars implies grid-filtered quantities. Inclusion of forest canopies in Eq. (1b) is done through the source terms $F_{f, i}$ added to the momentum equations as

$$
F_{f, i}=-C_{D} a_{f}|\bar{v}| \bar{v}_{i}
$$

where $C_{D}=0.15$ denotes the forest drag coefficient [103], $a_{f}$ is the vertical Plant Area Density (PAD) of the forest and $|\bar{v}|$ is the velocity magnitude. In Eq. (1b), the Smagorinsky subgrid model [104] is used to model the small scales given by

$$
\tau_{i j}-\frac{1}{3} \tau_{k k} \delta_{i j}=-\nu_{s g s} \bar{s}_{i j}
$$

$\bar{s}_{i j}=\frac{\partial \bar{v}_{i}}{\partial x_{j}}+\frac{\partial \bar{v}_{j}}{\partial x_{i}}$

$\nu_{s g s}=(\Lambda)^{2}\left(2 \bar{s}_{i j} \bar{s}_{i j}\right)^{1 / 2}$

$\Lambda=f_{v} \min \left\{\kappa d, C_{s} \Delta\right\}$

$f_{v}=1-\exp \left(\frac{-y^{+}}{A}\right)$

$\Delta=(\Delta x \Delta y \Delta z)^{1 / 3}$

where $\delta_{i j}, \nu_{s g s}, s_{i j}, f_{v}, \kappa, d, \Delta$ and $y^{+}$denote Kronecker delta, turbulent viscosity, strain rate tensor, van Driest damping function [105,106], von Karman constant, wall distance and filter-width computed by the local grid size, respectively. $C_{S}$ and $A$ are the constant model 


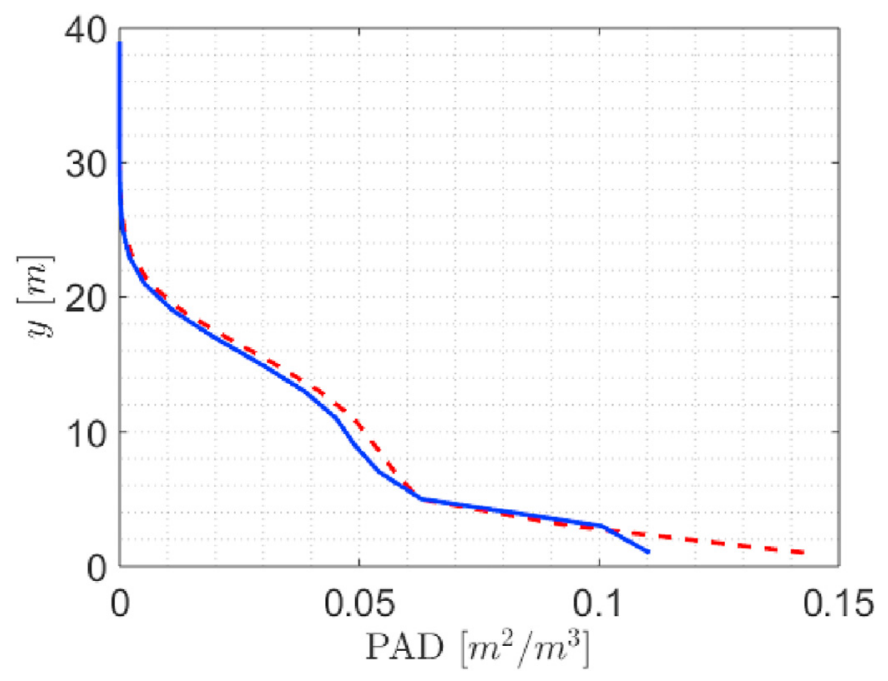

Fig. 8. Comparison between the mean PAD profile covered the computational domain (blue) and the local region (red) at Röbergsfjället site.

coefficients assumed to be 0.10 and 25.0 , respectively.

For the spatial and temporal discretization of the governing equations, a second-order bounded-central differencing scheme and a second-order time integration scheme are used, respectively.

\subsection{Boundary conditions}

Generally, the turbulence quantities inside the computational domain are dominated by the inlet conditions. Thus, the prescribed inlet profile must be cohered with upstream flow characteristics.

To supply the inlet boundary condition profiles for the complex terrain simulation, a precursor simulation is performed. The precursor simulation is carried out over a flat rectangular domain with periodic boundary conditions in the streamwise and spanwise directions. A symmetry boundary condition is employed at the top of the computational domain. Moreover, the ground is covered by homogeneous forest where the properties of the homogeneous forest is taken from the averaged vertical PAD profile computed from the heterogeneous forest distribution (see Fig. 8).

The computational domain consists of four different types of boundary conditions:

- Wall: No-slip wall boundary condition is set for the ground. The ground surface is assumed to be a smooth wall without any correction usually done by specifying the momentum flux from standard similarity theory [86] based on roughness length. The extracted spatial varying PAD profiles with a horizontal resolution of $20 \mathrm{~m} \times 20 \mathrm{~m}$ is specified at each grid point of the computational domain using the nearest-neighbour interpolation scheme.

- Inlet: The inlet boundary condition is specified as Velocity Inlet. It is chosen so that the calculated mean wind speed and the turbulence intensity at the met mast point (located at $60 \mathrm{~m}$ above the ground, in the vicinity of wind turbine 1 (WT1) with $5.2 \mathrm{~km}$ distance from the inlet boundary condition and in the mid-span of the computational domain) are $10 \mathrm{~m} / \mathrm{s}$ and 0.15 , respectively similar to the on-site measurement. The inlet boundary condition consists of the sheared mean velocity profile superimposed to turbulent fluctuations that is required in LES approach. The sheared mean velocity profile is taken from the precursor simulation as described above. The turbulent fluctuations at inlet are generated by an in-built function in STAR-CCM + the socalled Synthetic Eddy Method (SEM) [107]. The derived Reynolds stresses from the precursor simulation are specified as input into the SEM to provide the correlation function required by it. Since the flow is incompressible, the SEM scales the inflow fluctuations to maintain constant mass flow rate across the domain. The prescribed inlet boundary condition profiles are displayed in Fig. 9.

- Outlet: The Pressure Outlet boundary condition with zero gauge pressure is chosen at the outlet boundary condition.

- Top and Sides: Symmetry boundary condition is specified for the top and the sides boundaries. It must be noted that the symmetry boundary condition at the top boundary may lead to an artificial flow acceleration [108] because of the short distance between the highest point of the complex terrain and the top boundary. Therefore the minimum height of the domain has been chosen long enough to reduce the impact of the accelerated flow on the wind farm flow. Moreover, because of the imposed symmetry boundary conditions, the Coriolis force is not taken into account.

A constant time step of $t=0.1 \mathrm{~s}$ is used in the simulation to ensure that the Courant number is below one over the entire domain. However, for a few highly skewed grid meshes (due to the ground complex topography), there are negligible instances that the Courant number becomes greater than one. The simulation is carried out for $120 \mathrm{~min}$. The atmospheric turbulence and timevarying wind profile for the last $90 \mathrm{~min}$ of the simulation over the rotor swept area of all eight turbines are then extracted and exported to FAST for aerodynamic and aeroelastic analysis.

\subsection{Aeroelastic simulation of wind turbine}

In this paper, a comparison is made between homogeneous and heterogeneous terrain by evaluating the aero-servo dynamic loads experienced by wind turbine under the two different assumptions. The aim is to understand the effect of the terrain composition on the flow field and subsequently on the turbine loads giving us insight into the effect the terrain has on the turbine loads. The Röbergsfjället wind farm is equipped with 8 Vestas V90-2.0 [109] wind turbines that have a nominal electrical capacity of $2 \mathrm{MW}$. In this paper, a generic $2 \mathrm{MW}$ wind turbine model is developed to mimic the behavior/power production of a Vestas V90 machine. The state-of-the-art aeroelastic simulation tool FAST [98] is used for aeroelastic simulations of the wind turbine in this paper. The generic $2 \mathrm{MW}$ wind turbine model is developed by down-scaling the NREL 5 MW reference wind turbine [110] guided by Vestas V90-2.0 [109] power curve and the available SCADA data. For brevity, the step-by-step down-scaling procedure is not provided in this paper. It must be noted that the generic $2 \mathrm{MW}$ wind turbine model used here is not aimed to be an exact representation of a Vestas V90 wind turbine, but serves as a reference/baseline $2 \mathrm{MW}$ wind turbine model that mimics the performance of a $2 \mathrm{MW}$ Vestas V90 [109] turbine as shown in Fig. 10.

Two important categories of turbine loads are investigated, the along-wind loads on the blades and the tower and the high-speed shaft bearing loads. The loads on the blades and the tower are compared using the equivalent short-term damage equivalent loads and the bearing loads are compared using the equivalent bearing lives. In the following subsections a brief description of these quantities is presented. 


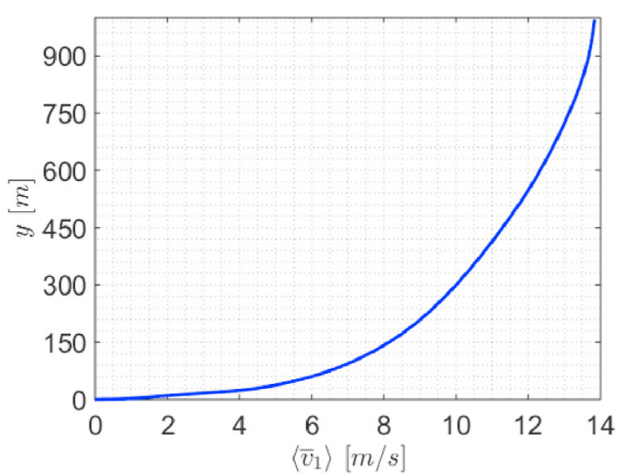

(a)

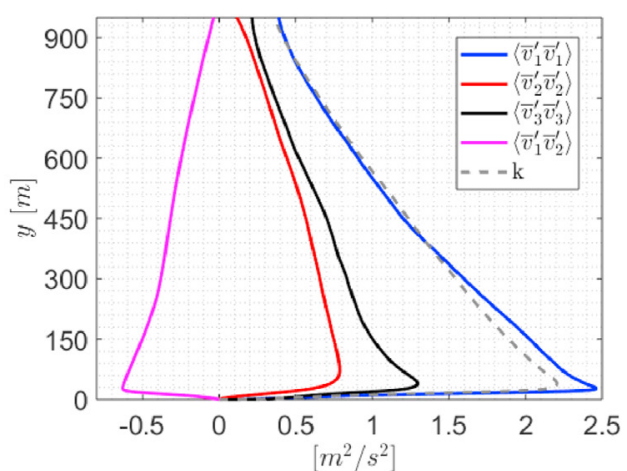

(b)

Fig. 9. The Prescribed inlet boundary condition profiles obtained from the precursor simulation.

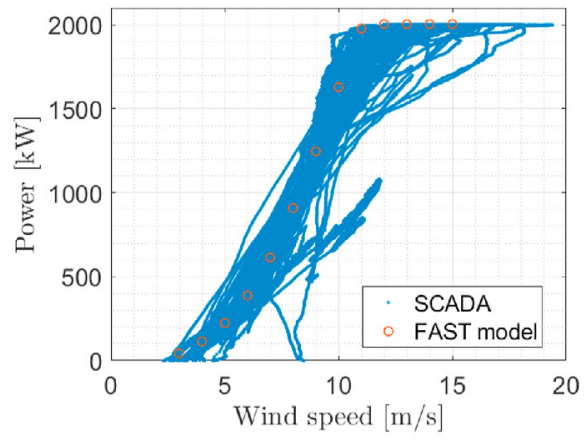

(a)

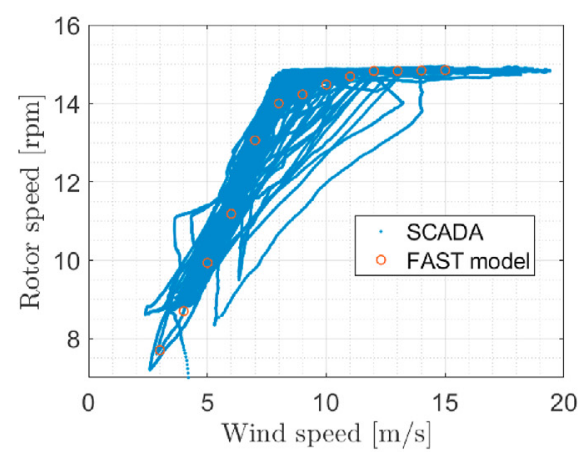

(b)

Fig. 10. Comparison of SCADA data against FAST model, (a) Generator power, (b) Rotor speed.

\subsection{Estimation of short-term damage equivalent turbine loads}

The along-wind loads on the blades and the tower is used for comparison as their magnitude is higher than the cross-wind loads experienced by the turbine. The loads considered here are: Blade 1 root flapwise bending moment (named Bl1RootFlpMom in FAST); Tower base fore-aft bending moment (TwrBsFAMom); and, Tower top yaw bearing moment (TTYawMom). These measurements are available directly as outputs from FAST [98]. However, for appropriate comparison, the structural loads are compared using the short-term damage equivalent loads (DELs) estimated from a 90 min time history prediction. The short-term fatigue damage equivalent loads (DELs) [111,112] are calculated on the basis of the output times series, which, for a given mean wind speed, is determined by

$D E L=\left(\frac{1}{N_{e q}} \sum_{i} n_{i}\left(\Delta F_{i}\right)^{m}\right)^{1 / m}$

where $n_{i}$ is the number of load cycles with range $\Delta F_{i}$ in a time series, $i$ is the fatigue cycle index, $m$ is the Wholer exponent, and $N_{e q}=f^{e q} T$ where is $f^{e q}$ the DEL frequency, and $T$ is the elapsed time of the timeseries under consideration. The short-term DELs have been estimated using Mlife [113] distributed by the National Renewable Energy Laboratory (NREL).

\subsection{Estimation of high-speed shaft bearing life}

The drive-train/gearbox of the wind turbines are one of the most critical component of a wind turbine [114]. The schematic diagram of the high-speed shaft can be seen in Fig. 11. Typically, the highspeed shaft bearings have the highest failure rates [115]. Hence, it is important to understand and predict the behaviour of the highspeed shaft bearing loads under the two different types of forest assumptions. The high-speed shaft cylindrical roller bearing life is used in this paper for comparison. The High-Speed Shaft Cylindrical Roller Bearing (HSS-CRB) life is estimated using the high-speed shaft cylindrical roller bearing radial force $\left(F_{r}\right)$. As this quantity is not available directly as an output from FAST [98], a approximate procedure of estimating the radial bearing force from the highspeed shaft torque (available as a direct output from FAST [98]) is presented next.

On the high-speed shaft in Fig. 12, from torque balance it can be observed that

$T=F_{t} r$

where, $T$ is the high-speed shaft torque, $F_{t}$ is the tangential force, $r$ is the working pitch radius of the pinion.

The helical gear's transmission/gear-pair force, $F_{n}$, which is normal to the tooth surface, can be resolved into a tangential component, $F_{1}$, and a radial component, $F_{r}$, as

$F_{1}=F_{n} \cos \alpha_{n}$

$F_{r}=F_{n} \sin \alpha_{n}$

where, $\alpha_{n}$ is the normal pressure angle. The tangential component, $F_{1}$, can be further resolved into circular sub-components, $F_{t}$, and axial thrust sub-component, $F_{X}$ as 


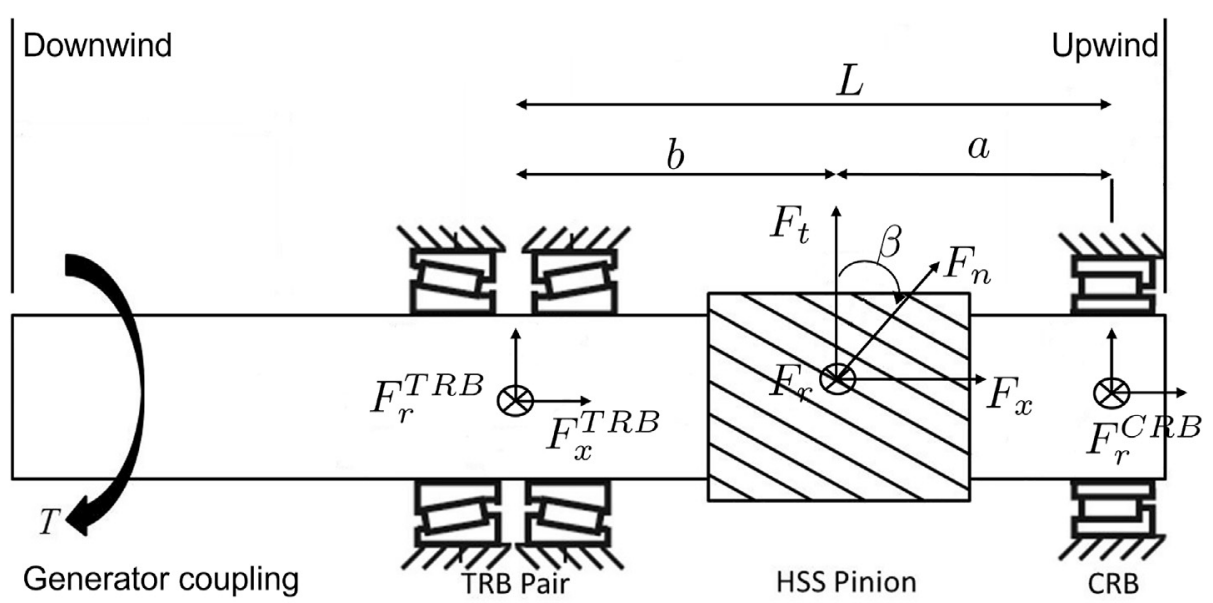

Fig. 11. Schematic diagram of the high-speed shaft.

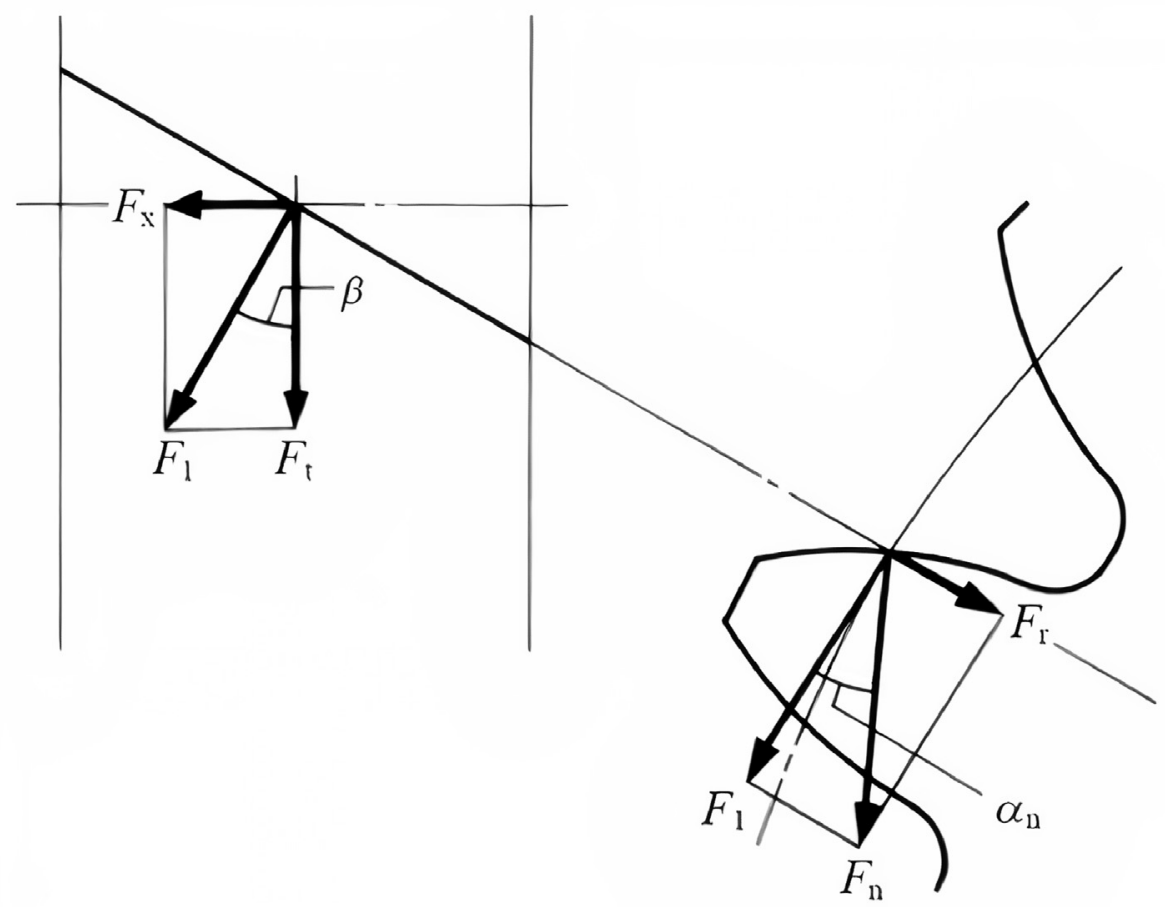

Fig. 12. Forces on a helical gear mesh.

$F_{t}=F_{1} \cos \beta$

$F_{x}=F_{1} \sin \beta$

where, $\beta$ is the helix angle. Then, using simply supported beam assumption the resultant bearing forces on the tapered roller bearing (TRB) and cylindrical roller bearing (CRB) as shown in Fig. 12 can be estimated as

$$
\begin{aligned}
& F^{T R B}=\sqrt{F_{r}^{2}+F_{t}^{2}}\left(\frac{a}{L}\right) \\
& F^{C R B}=\sqrt{F_{r}^{2}+F_{t}^{2}}\left(\frac{b}{L}\right)
\end{aligned}
$$

while it is assumed that the axial forces are taken up by the TRB alone. These equations, although approximate, provides us with a good estimation of a radial bearing forces from high-speed shaft torque. This estimated radial bearing forces can be used now to estimate the bearing life.

The fatigue life of an individual bearing is the number of revolutions (or the number of operating hours at a constant speed) that the bearing operates before the first sign of metal fatigue (rolling contact fatigue (RCF) or spalling) occurs on one of its rings or rolling elements. The rating life $L_{10}$ is the fatigue life that $90 \%$ of a sufficiently large sample of identical bearings operating under identical conditions can be expected to attain or exceed. For a given bearing, its fatigue life can be predicted using simplified equations as shown in Ref. [116]. These predictions although not highly accurate, together with engineering experience and judgement provide a good basic for bearing selection.

For applications like wind turbines the operating conditions, such as the magnitude and direction of loads, speeds, temperatures 
and lubrication conditions, are continually changing. In these cases, the load spectrum can be reduced to a histogram plotting constantload blocks. Each block characterizes a given percentage or timefraction during operation. Heavy and normal loads consume bearing life at a faster rate than lighter loads. Therefore, it is important to have peak loads well represented in the load histogram, even if the occurrence of these loads is relatively rare and of relatively short duration. Under variable operating conditions, bearing life can be rated using

$L_{10 m}=\frac{1}{\sum_{i} \frac{N_{i}}{L_{10 m}^{i}}}$

where

\section{Results}

\subsection{Validation against met mast}

The time-averaged grid-filtered axial wind velocity $\left\langle\bar{v}_{1}\right\rangle$ and streamwise turbulence intensity $T I_{u}=\left\langle\bar{v}_{1}^{\prime 2}\right\rangle^{0.5} /\left\langle\bar{v}_{1}\right\rangle$ at the met mast location, obtained from the simulation for a period of $90 \mathrm{~min}$ is compared against the measurement data in Fig. 13. The $\mathbf{\square}$ and the error bars display the mean value and the $\min / \max$ of the measured quantities at $40 \mathrm{~m}$ and $60 \mathrm{~m}$ heights above the ground in the dominant wind direction i.e., $216^{\circ}$ w.r.t. North, respectively. The power spectral density of axial wind velocity $\left(\bar{v}_{1}\right)$ at $60 \mathrm{~m}$ height above the ground at the met mast location is also presented in Fig. 13(c). It follows a $-5 / 3$ decay and drops after the cut-off fre-

$L_{10 m}=\operatorname{SKF}[116]$ rating life (at 90\% reliability) [million revolutions]

$L_{10 m}^{i}=\operatorname{SKF}[116]$ rating lives (at 90\% reliability) under constant condition $i$ [million revolutions]

$N_{i} \quad=$ life cycle fraction under condition $i ; \sum N_{i}=1$

quency of $f=0.1 \mathrm{~Hz}$ limited by the grid resolution in the simulation.

\subsection{Validation against SCADA}

The LES predicted wind field is compared to wind speed as

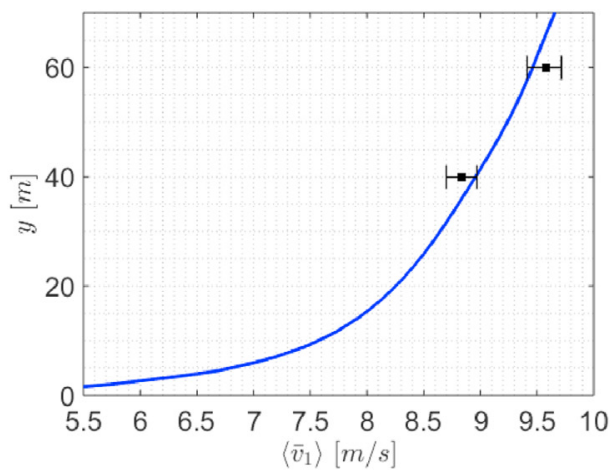

(a)

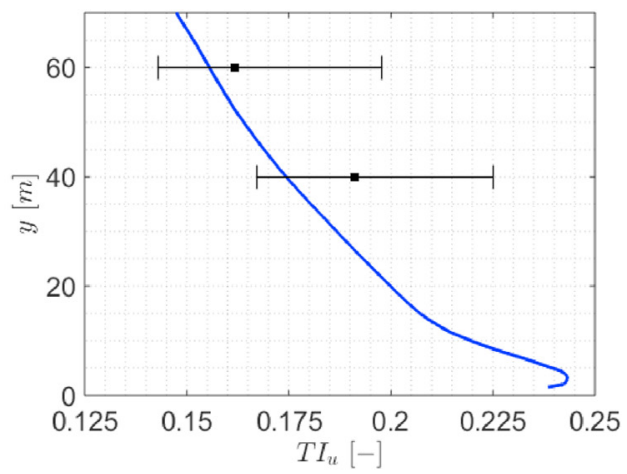

(b)

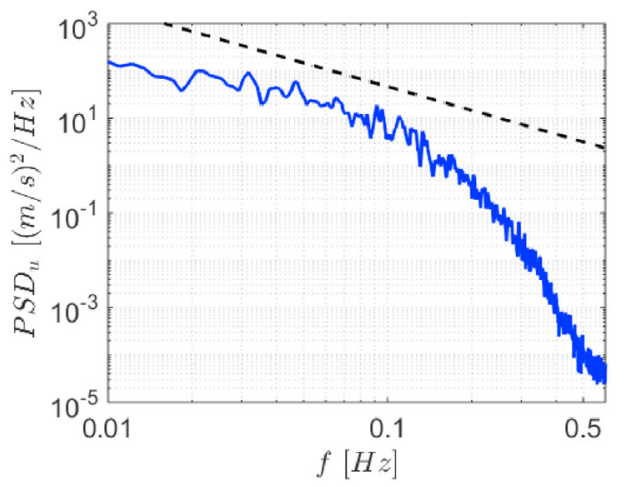

(c)

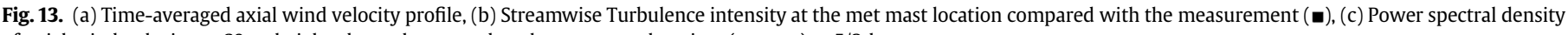
of axial wind velocity at $60 \mathrm{~m}$ height above the ground at the met mast location, (-n- - ) - 5/3 law. 
recorded by nacelle anemometer and collected through the wind turbine's SCADA system on WT1-WT8. For the site under consideration, $1 \mathrm{~Hz}$ SCADA data is available (with some losses) from $20^{\text {th }}$ June 2017 to $3^{\text {rd }}$ February 2019. The LES simulations are carried out at $10 \mathrm{~m} / \mathrm{s}$ inlet velocity, $216^{\circ}$ to north, under assumption of neutral atmosphere. Also, the LAD/PAD was measured when trees had leaves. Therefore, 10-min samples of SCADA data are extracted when WT1 (which is adjacent to the met mast) wind speed satisfies the following conditions: mean wind is $10.32 \pm 1 \mathrm{~m} / \mathrm{s}$, turbine yaw direction is $216 \pm 7^{\circ}$ to north, time is $11: 00-17: 00 \mathrm{~h}$ and is outside the period Oct 1st to May 1st. For comparison, a less restrictive set of samples is collected where the daytime and summer time criteria are ignored, and only wind speed and direction is considered. A few instances of samples where at least one turbine was out of operation and did not report data were discarded.

The anemometer data is likely disturbed by the rotor and it is assumed that wind speed data is similarly disturbed at all turbines. Moreover, to avoid bias from the distribution of wind speed samples within the chosen wind speeds, the difference in wind speed between turbines are chosen as evaluation criteria over the absolute values. Level of turbulence is compared using the turbulence intensity (TI) values since $\mathrm{TI}$ is dimensionless. The results form comparison are presented in Fig. 14 and Fig. 15.

In Fig. 14 the difference in wind speed of turbine WT2-WT8 compared to WT1 is presented together with the difference as predicted by the LES in Table 1. Fig. 15 compares turbulence intensity from the same SCADA samples with TI as predicted by LES simulations in Table 1.

In terms of mean wind speed differences, as displayed in Fig. 14, SCADA data reports a lower wind speed (negative differences) for all turbines than LES, most prominent for turbines WT3, WT4 and WT7. It is interesting to note, that a more restrictive set of wind conditions that are more likely to target neutral atmospheric conditions (black) is closer to the LES-predicted wind speeds (red). From the comparison in Fig. 15, a good agreement is obtained for turbines WT5, WT7 and WT8, while poorer agreement is obtained for the remaining turbines. For all turbines but WT7, the more restrictive samples (black) have a mean closer to the TI as predicted by LES. As seen from Fig. 16(d), turbines WT1, WT5, WT7 and WT8 have no immediate other turbine upstream. Since no effect from turbine on the wind field is considered in the LES simulations in this study (for instance using actuator disk model) it can be assumed the TI level predicted by LES underestimates the actual TI for WT2, WT3, WT4 and WT6. This assumption is confirmed by the comparison in Fig. 15. No attempt of using SCADA to compare to LES predicted wind shear is made.

\subsection{Flow characteristics over the entire wind farm}

Fig. 16(a) and (b) display the iso-surface of the horizontal mean

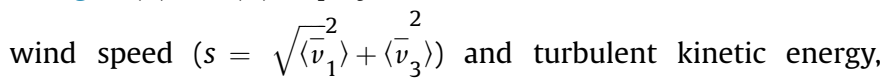
defined as $k=\frac{1}{2}\left\langle v_{i}^{\prime \prime} v_{i}^{\prime}\right\rangle$, at hub height (i.e., $90 \mathrm{~m}$ above the ground) for a period of $90 \mathrm{~min}$. All turbines have been located at the highest elevation compared to the surrounded area. As seen, wind turbine WT1, WT7 and WT8 have greater hub-height mean wind speed than the other turbines, mostly related to their elevations level. On the other hand, WT2, WT6 and WT4 experience higher inflow turbulent kinetic energy at hub height than the others. This motivates the study of inflow properties at each wind turbine station in more detail.

\subsection{Flow characteristics at turbines' location}

Fig. 17(a) shows the time-averaged grid-filtered wind velocity

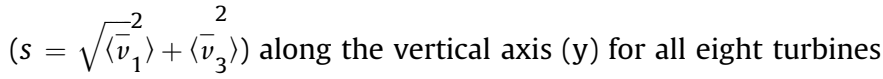
extracted for a period of $90 \mathrm{~min}$. As seen, the mean wind profiles vary w.r.t. the turbines' location because of the terrain complexity and forest canopies heterogeneity. In addition to the mean wind profile, each turbine encounters a different level of turbulence represented by the turbulent kinetic energy $(k)$ in Fig. 17(b). A large difference in mean wind velocity and turbulent kinetic energy profiles between the lower section (from $45 \mathrm{~m}$ to $90 \mathrm{~m}$ ) and the upper section (from $90 \mathrm{~m}$ to $135 \mathrm{~m}$ ) of the rotor plane make
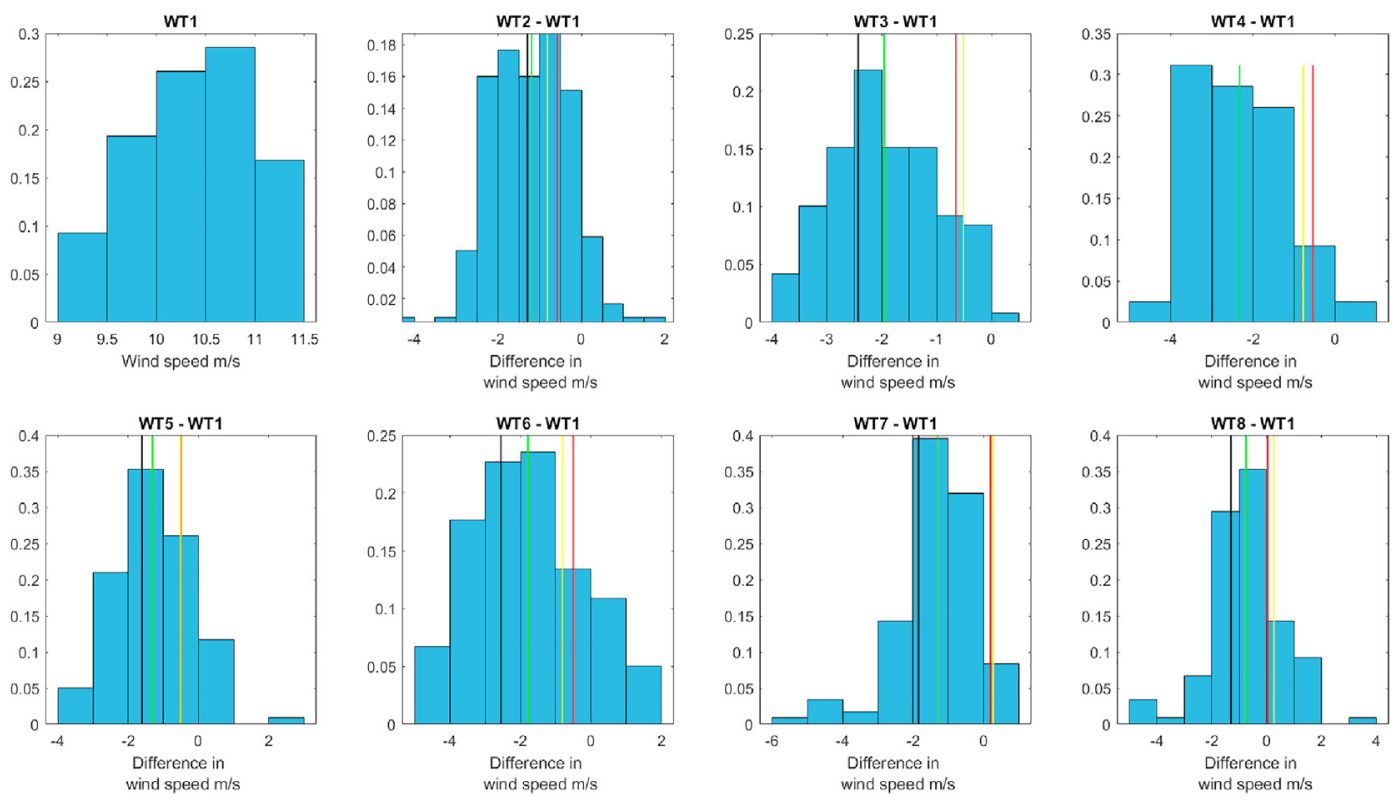

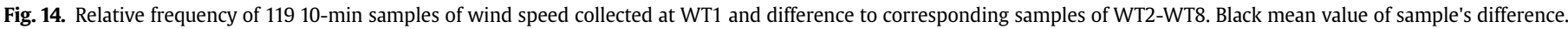

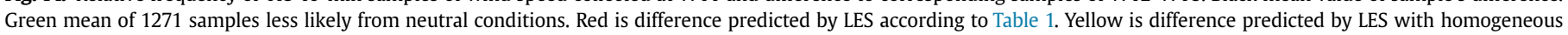
forest assumption. 

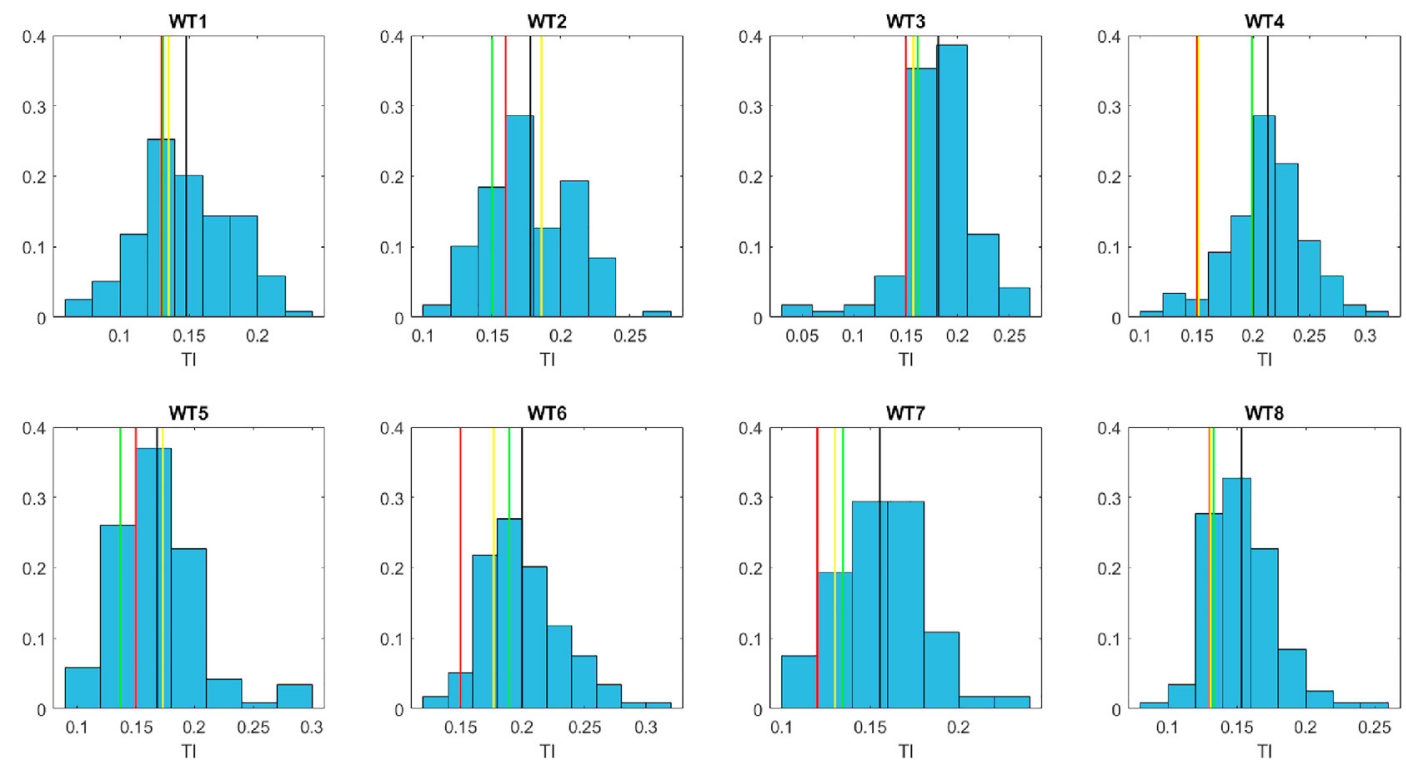

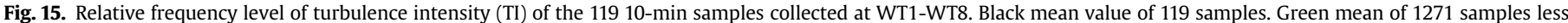
likely from neutral conditions. Red TI predicted by LES according to Table 1. Yellow TI predicted by LES with homogeneous forest assumption.

additional undesirable cyclic forces and moments variations. Fig. 17(c) and (d) display 90 min time-averaged wind veer $(\varphi)$ and yaw $(\gamma)$ angles along the vertical axis $(y)$ for all eight turbines, respectively. Although the inlet inflow profile is veer and yaw-free and the Coriolis force is not taken into account, the mean wind direction varies both vertically (veer) and horizontally (yaw). Contrary to the mean wind veer angle $(\varphi)$ which is almost constant along the (y) axis, the mean wind profile tends to turn in the vertical direction. This reveals that the turbines located in a complex terrain covered by a heterogeneous forest are exposed to a nonuniform yawed and inclined flows over the rotor area.

As mentioned in sub-section 2.1, the on-site measurement was done by means of a meteorological mast with two cup anemometers at $40 \mathrm{~m}$ and $60 \mathrm{~m}$ above the ground. Because of the terrain complexity and canopies heterogeneity, the flow field would vary around each wind turbine in the wind farm. Therefore, one meteorological mast is not sufficient to accurately assess the wind resource across the wind farm.

To evaluate how much the flow field at the turbines' location differ from the met-mast location, the mean wind speed and turbulent kinetic energy profiles of each turbine are normalized by the corresponding profiles at the met-mast location i.e., $s_{M M}$ and $k_{M M}$. As can be seen in Fig. 18(a), except for the wind turbines WT1, WT7 and WT8, the normalized mean wind speed $\left(s / s_{M M}\right)$ along the $(\mathrm{y})$ axis is lower than the met-mast location. The normalized turbulent kinetic energy $\left(k / k_{M M}\right)$ shown in Fig. 18(b) demonstrates that all the turbines, apart from WT1, are confronted by a higher turbulence than the met mast location.

Generally, the wind shear and turbulent kinetic energy across the rotor have significant impact on aero-structural dynamics of a wind turbine. Apart from various atmospheric parameters, they are substantially driven by the terrain complexity and canopies heterogeneity. Remarkable variation in vertical direction reveals that more detailed analysis must be done to quantify the impact of the mean wind speed and shear as well as the inflow turbulence on power production and structural response of each turbine in a wind farm. Instead of single-point evaluation (e.g., hub height), the axial mean wind speed for a period of $90 \mathrm{~min}$ is computed by the timeintegration of the rotor equivalent wind speed $\left(U_{E q}\right)$ to include the impact of wind shear over the rotor swept area. According to IEC 61400-12-1:2017 standard (Wind energy generation systems-Part 12-1: Power performance measurements of electricity producing wind turbines) [117], the rotor equivalent axial wind speed is determined as

$U_{E q}=\left(\sum_{i=1}^{n} \bar{v}_{1, i}^{3} \frac{A_{i}}{A}\right)^{1 / 3}$

where $n, \bar{v}_{1, i}$ and $A_{i}$ denote the number of vertical segments, gridfiltered instantaneous axial wind speed at height $i$, the rotor swept area and the area of $i$ th segment associated with $\bar{v}_{1, i}$.

In the neutral $\mathrm{ABL}$, the wind shear exponent mainly varies with altitude and surface roughness. The impact of the vertical wind shear due to the planetary boundary layer is more pronounced because of the cyclic behaviour of the rotor at high mean wind speed. A large vertical wind shear makes a considerable imbalance air loads acting on rotor blades resulting in significant fatigue loads and component failures, such as gearbox bearing [118].

The hub height and rotor radius of the existing wind turbines at Röbergsfjället site are $90 \mathrm{~m}$ and $45 \mathrm{~m}$, respectively. For a turbine with large rotor diameter exposed to an unsteady and complex flow field, the wind profile across the rotor does not smoothly follow the power law. Therefore, following the IEC 61400-12-1:2017 standard [117], three heights has been chosen to compute the wind shear exponent over the entire rotor area, i.e., the bottom of rotor plane at $45 \mathrm{~m}$, the hub height at $90 \mathrm{~m}$ and the top of the rotor plane at $135 \mathrm{~m}$ above the ground.

The instantaneous longitudinal velocity $\left(\bar{v}_{1}\right)$ is used to calculate the instantaneous wind shear exponent for the lower $\left(\alpha_{1}\right)$ and the upper $\left(\alpha_{2}\right)$ sections of the rotor plane on the basis of the power law equation given by [119].

$\frac{\alpha_{1}=\ln \left(\bar{v}_{1,45} / \bar{v}_{1,90}\right)}{\ln \left(y_{45} / y_{90}\right)}$ 


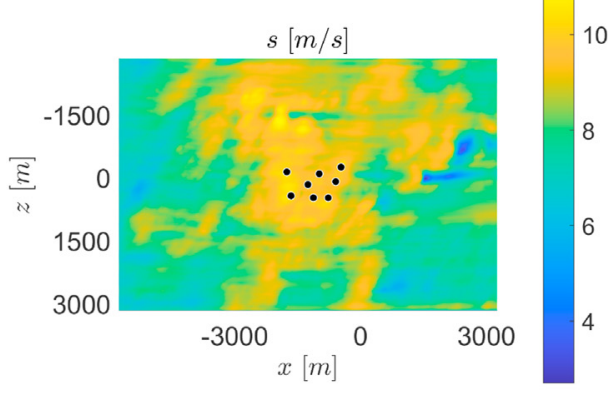

(a)

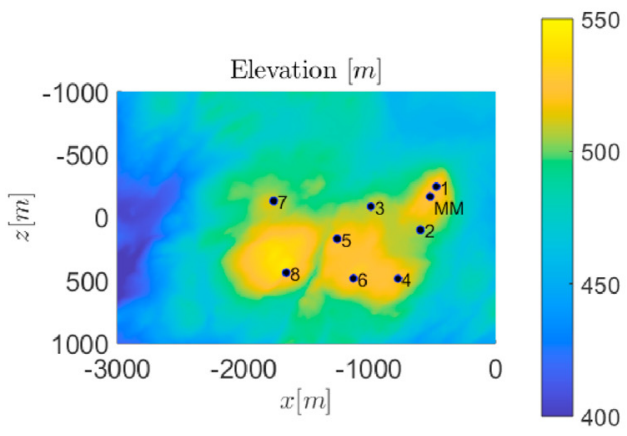

(c)

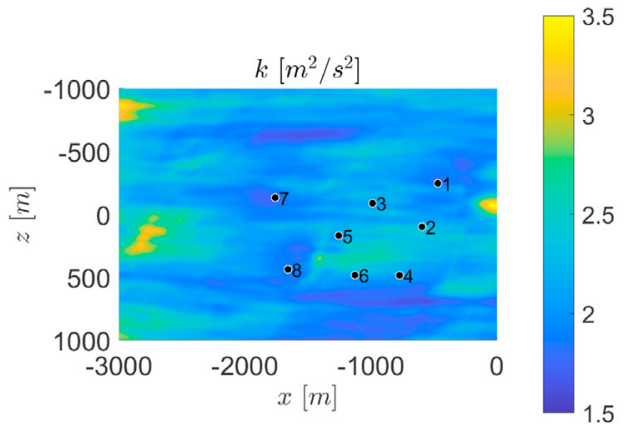

(e)

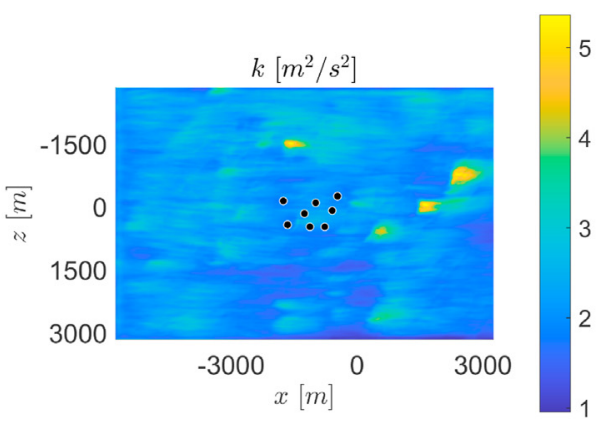

(b)

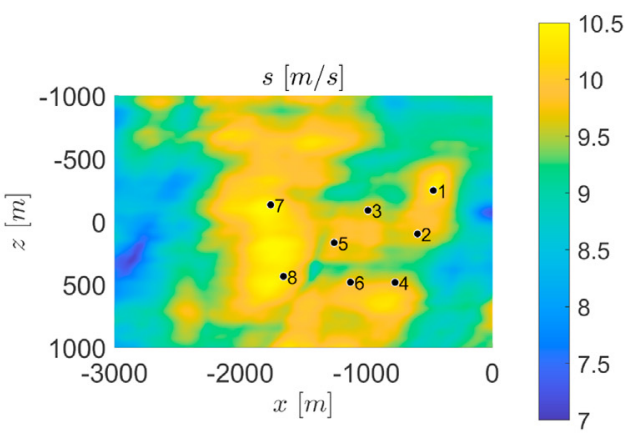

(d)

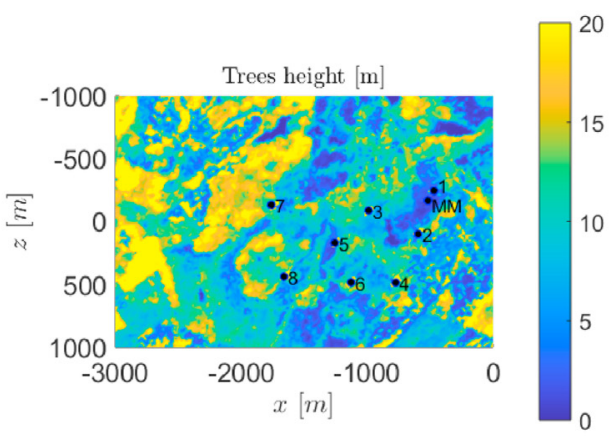

(f)

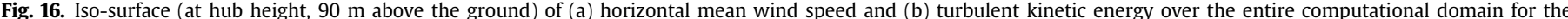

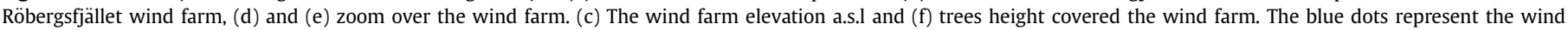
turbine's location. MM denotes Met-Mast location too.

$\frac{\alpha_{2}=\ln \left(\bar{v}_{1,90} / \bar{v}_{1,135}\right)}{\ln \left(y_{90} / y_{135}\right)}$

Table 1 presents a summary of the axial mean wind speed at hub height $\left\langle\bar{v}_{1}\right\rangle_{h u b}$, the mean equivalent axial wind speed $U_{E q}$, wind shear exponents $\left(\alpha_{1}\right.$ and $\left.\alpha_{2}\right)$ and the rotor equivalent turbulence intensity $T I_{U_{\mathrm{Eq}}}$ statistics over the entire rotor for a period of $90 \mathrm{~min}$. Except WT7 which is the third from last (antepenultimate) in terms of the altitude, $U_{E q}$ is related to the higher mean wind speed at higher elevation.

The difference between the axial mean wind speed at hub height $\left\langle\bar{v}_{1}\right\rangle_{h u b}$ and the mean equivalent axial wind speed $U_{E q}$ is below $1 \%$ at each turbine location. Therefore, the hub height can be taken as the reference point.

According to the logarithmic wind profile, the wind shear exponent $(\alpha)$ is a function of effective surface roughness length $\left(y_{0}\right)$ and elevation above the surface ( $y$ ) given by $\alpha=1 / \ln \left(y / y_{0}\right)$. The effective surface roughness length in the neutral ABL is strongly affected by the ground topography and surface roughness element such as heterogeneous forest structure characterized by the trees height and density [120]. In addition, the power law exponents, collected for different types of terrains [121], vary from 0.1 for smooth surface and open water to 0.25 for many trees and hilly terrain. As observed, the mean shear exponents vary at each wind turbine location justifying the impact of upstream ground 


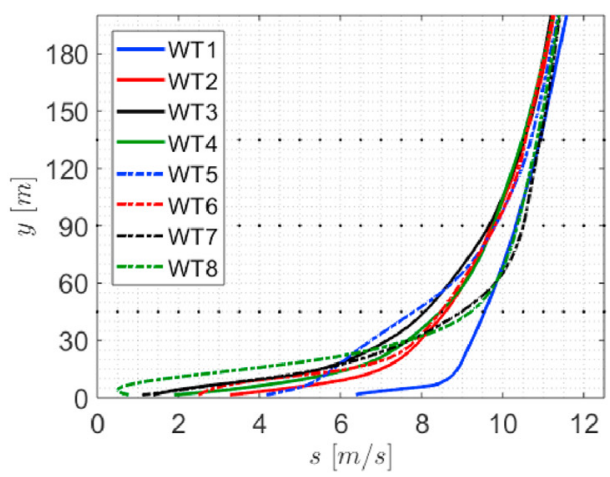

(a)

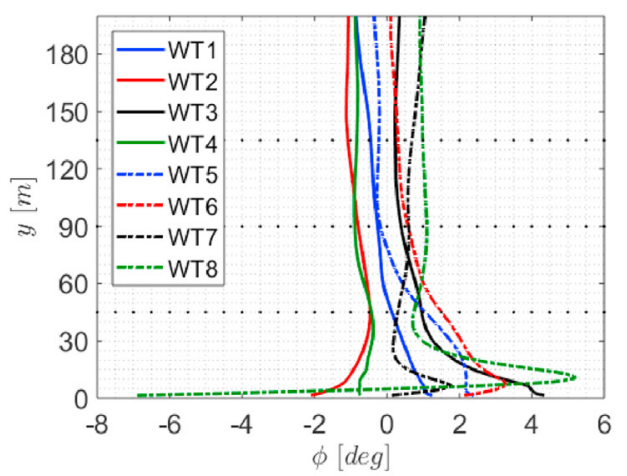

(c)

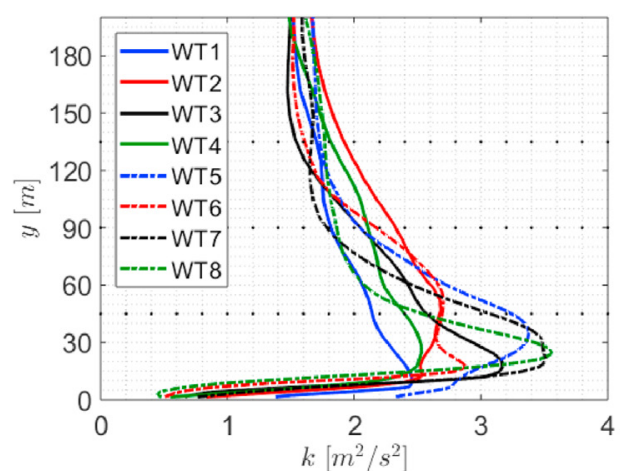

(b)

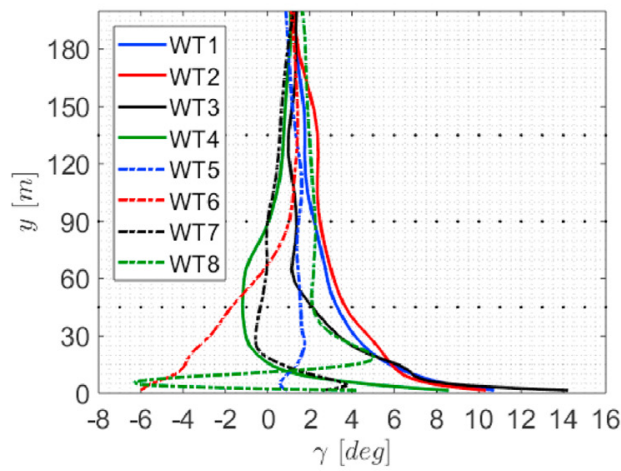

(d)

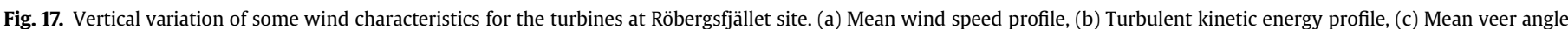
profile and (d) Mean yaw angle profile. The rotor swept area limits and hub height at $90 \mathrm{~m}$ are illustrated by $(\cdots)$.

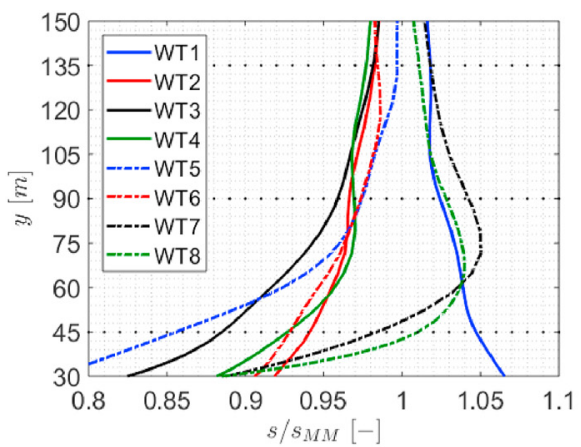

(a)

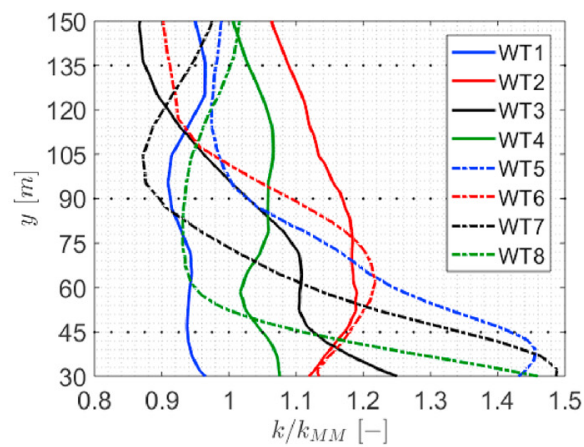

(b)

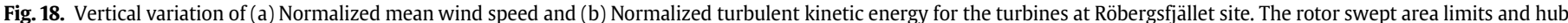
height at $90 \mathrm{~m}$ are illustrated by the dotted line $(\cdots)$.

complexity indicated by effective surface roughness. The minimum mean shear exponent occurs at the location of WT1 whereas WT5 has the maximum one. The absolute difference between the mean shear exponent at the lower and upper sections of the rotor area defined as $\Delta_{\alpha}=\left|\alpha_{1}-\alpha_{2}\right|$ may induce additional bending moment acting on rotor blades. WT7 and WT2 are subjected to the highest and lowest $\Delta_{\alpha}$ among all other turbines, respectively. The potential impact of $\Delta_{\alpha}$ on the bearing life of the turbines will be studied in section 4.9.

Except for WT1 and WT7 with minimum and WT2 with maximum rotor equivalent turbulence intensity, other turbines are exposed to the same level of inflow turbulence. Furthermore, the rotor equivalent turbulence intensity $T I_{U_{\mathrm{Eq}}}$ for all turbines are below $13 \%$ which corresponds to the turbulence intensity of class C in IEC61400-1 standard [100] as shown in Fig. 5.

\subsection{Flow Evolution}

Wind turbines are operating within the Atmospheric Boundary Layer (ABL) ranging from 150-1500 $\mathrm{m}$ [120]. Normally, the lowest part of the ABL, the so-called surface layer extends up to $10 \%$ of the ABL height where the wind speed vary with height [122]. In neutral $\mathrm{ABL}$, the air flow within the surface layer is characterized as a highReynolds number turbulent flow generated by large velocity 


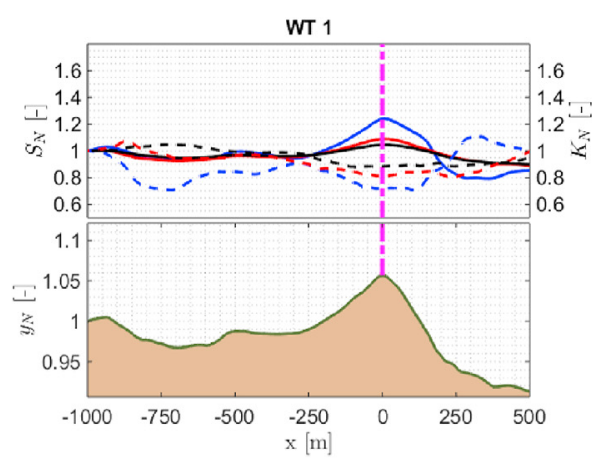

(a)

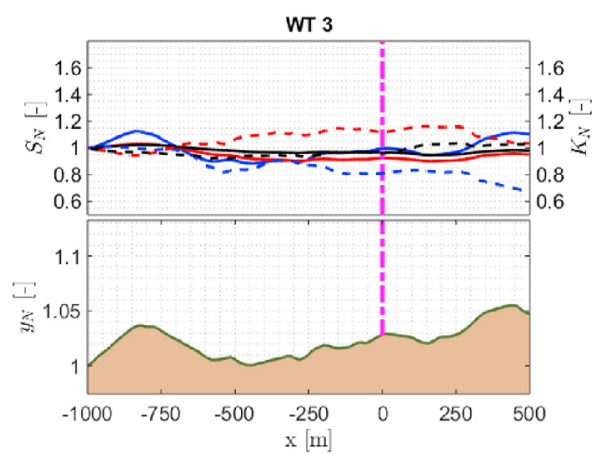

(c)

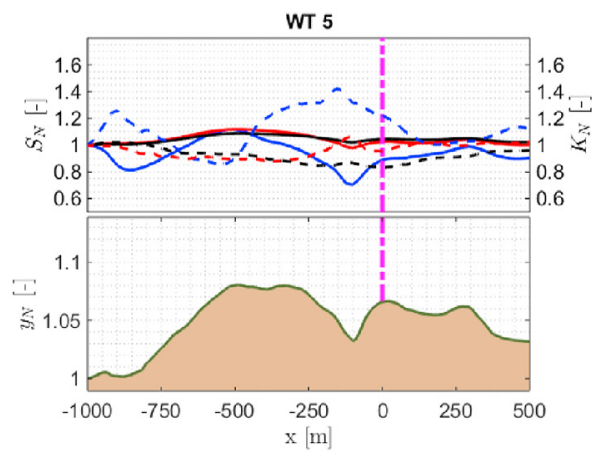

(e)

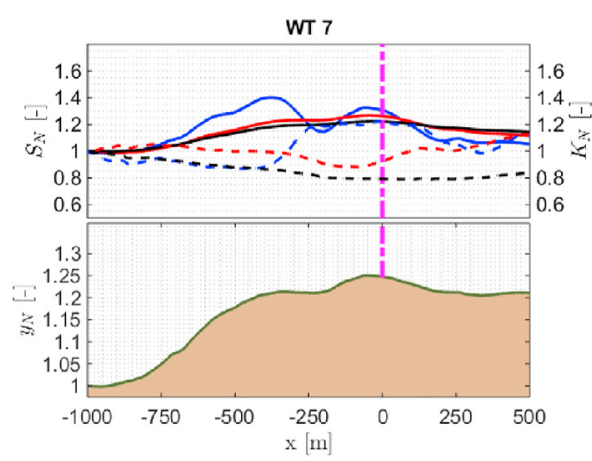

(g)

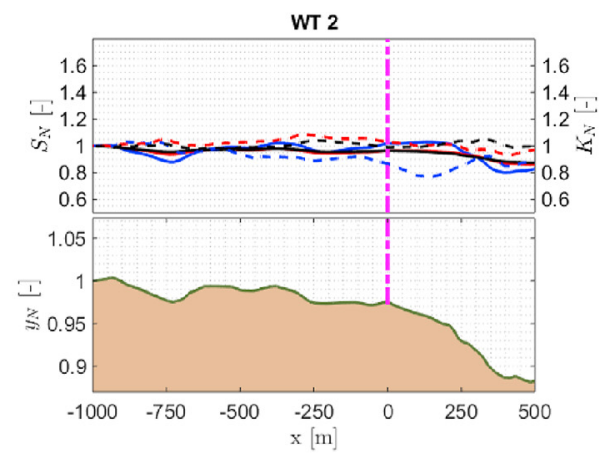

(b)

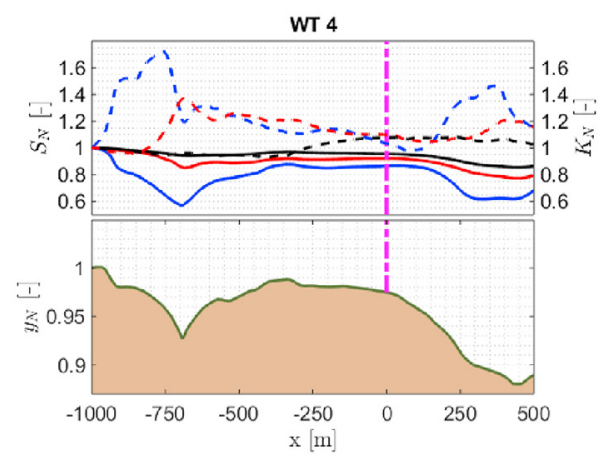

(d)

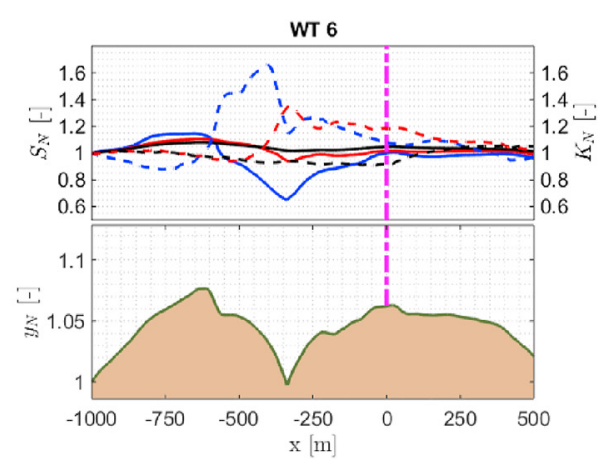

(f)

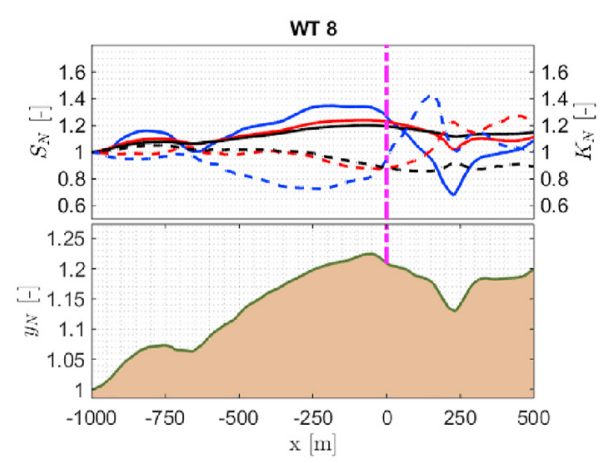

(h)

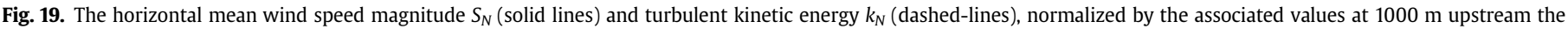

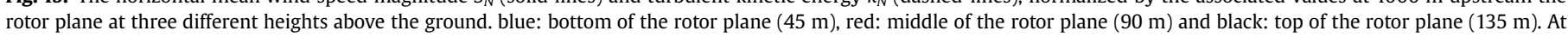
each wind turbine location, the ground elevation $y_{N}$ is also normalized by the altitude at $1000 \mathrm{~m}$ upstream the rotor plane. 
gradients in the vertical direction. The generated turbulence is transported to the air stream through the upward surface layer momentum flux. As previously mentioned in sub-section 2.1, in the neutral $A B L$, the mean wind speed profile and turbulent kinetic energy strongly depend on the surface roughness i.e., terrain complexity and canopies heterogeneity. In other words, the surface roughness plays a major role in the motion of turbulent flow structures inside the neutral ABL.

Fig. 19 displays the variation of flow field at three different heights above the ground for the wind turbines' at Röbergsfjället

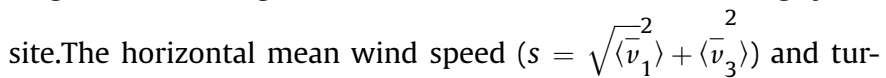
bulent kinetic energy $(\mathrm{k})$ at each elevation is normalized by the associated values at $1000 \mathrm{~m}$ upstream the rotor plane as $S_{N}=s / s_{1000}$ and $K_{N}=k / k_{1000}$, respectively. It can be seen that $S_{N}$ rapidly react to the terrain topography at low elevation up to the hub height at $90 \mathrm{~m}$.

The impact of the windward slope measured between the turbines' location and $1000 \mathrm{~m}$ upstream on $S_{N}$ is obvious. Apart from WT2 and WT4 with negative windward slope, WT1, WT3, WT5 and WT6 are located on a very gentle slope showing a smooth speed up. The maximum speed up occurs for WT7 and WT8, respectively because of their moderate windward slopes.

The steep-sided valleys, located upstream WT4, WT5 and WT6 and downstream of WT8, decrease $S_{N}$ at low elevation. This reduction can be partially recovered by a very strong slope after a steep-sided valley. Furthermore, recirculation regions occur at these steep-sided valleys. These regions are characterized by low mean wind speed (s) and high turbulent kinetic energy (k). Unlike the mean wind speed, the sensitivity of turbulent kinetic energy to the terrain topography extends above the hub height denoting the motion of large-scales turbulent structures inside the wind farm. In addition to the terrain complexity, the heterogeneity of forest canopies has a considerable effect on the turbulence generation mechanism especially at the forest edge. For instance, the sudden change in $k_{N}$, as seen in Fig. 19(e) and (g), occurs at a constant ground elevation and it can be translated to the abrupt change in surface roughness caused by the forest properties.

\subsection{Deflection and inclination of mean flow}

The airflow within a wind farm is distorted by the surface roughness heterogeneity including complex topography and ground's heterogeneous vegetation. The deflected airflow have a large impact on the aerodynamics of rotor blades. Fig. 20 presents the streamlines of the vertical and lateral mean wind velocities around the rotor planes. The colorbar indicates the magnitude of the peripheral mean wind speed normalized by the axial mean wind speed. As seen, the peripheral mean wind speed magnitude is the largest at WT2 and the lowest at WT7. The ratio between the peripheral and axial mean wind speeds is limited by 0.12 , however variation in turbulent flow structures can be clearly identified. In particular, the flow structure over the swept rotor of WT4, WT6 and WT7 dramatically change in both horizontal and vertical directions which makes a flow turning across the rotor. Generally, the horizontal and vertical misalignment of the incoming flow with respect to the rotor axis, the so-called yawed flow and inclined flow, respectively induce additional load and moments at rotor blades [123]. But the mean flow turning over the entire rotor (like WT4, WT6 and WT7) causes the upper and lower halves of the rotor blades to expose to an undesirably imbalanced load and moments distribution.

\subsection{Impact of surface roughness on turbulence}

In the neutral $\mathrm{ABL}$, the turbulence inside the wind farm is mainly generated by the surface roughness affecting largely the aerodynamics and structural dynamics of the rotor blades. However, the prediction of airflow and development of turbulent flow structures over the complex topography covered by non-uniform vegetation and forest canopies (characterized by vertically varying Plant Area Density (PAD) and height) is challenging [94]. In neutral ABL canopy flow, the acceleration and deceleration of the mean flow mainly taking place at the forest edge is considered as the primary source of the turbulent kinetic energy budget [124].The importance of the turbulent structures generated at the forest edge is due to the fact that they are convected to the upper layers of the air flow. Their size and strength are steadily grown up to satisfy the equilibrium between the airflow and surface roughness which accordingly affect the flow passing through the rotor area. Moreover, in neutral ABL flow over the hilly terrain covered by the heterogeneous forest, the horizontal variation of PAD, the maximum PAD height and the separated flow by the ground topography increase the difficulties of numerical modelling of wind flow inside and above the forest especially on the turbulence generation mechanisms. Fig. 21 demonstrates the turbulence generation caused by the complex terrain and heterogeneous forest at each wind turbine's location within the Röbergsfjället wind farm. As seen, the turbulent kinetic energy below the forest edge is low and grows rapidly towards the edge of the forest. Moreover, in some locations, the turbulence generation is much higher where they are mostly associated with the denser forest edges [125] and steep-sided valleys. At the denser forest edge, the strong shear due to the acceleration and deceleration of the mean flow is the main source for the production of the turbulent kinetic energy. In steep-sided valleys corresponding to the recirculation region, the production of turbulent kinetic energy occurs at separation zone which is slightly before the valley trough.

\subsection{Comparison of short-term damage equivalent turbine loads}

A summary of the short-term damage equivalent loads (DELs) for Blade 1 root flapwise bending moment (Bl1RootFlpMom), Tower base fore-aft bending moment (TwrBsFAMom) and Tower top yaw bearing moment (TTYawMom), obtained from numerical simulations, are provided in Table 2 . These quantities are obtained from 90 min time-history predictions obtained from FAST. It can be observed that the damage equivalent loads are higher, on an average, under the homogeneous forest assumption. The main reason for this increase is the higher turbulence in the flow-field under the homogeneous forest assumption. Generally, in the homogeneous forest assumption, the ground is uniformly covered by the forest canopies with the same PAD profile. Therefore, additional turbulence due to forest canopies are generated everywhere in the computational domain through the drag term in the momentum equation (Eq. (1b)). However, in the heterogeneous forest assumption, because of the scattered forest canopies with varying PAD profiles, the drag term in the momentum equation (Eq. (1b)) is more likely to be smaller than the homogeneous forest which in turn produce less turbulence. It must be noted here that although the DELs reported here are short-term, they provide an indication of structural load trends presented by the two different terrain assumptions. It is also important to note that these results are site specific. For another site, the turbulence intensity associated with heterogeneous forest (in case of higher forest density) assumption may be higher than homogeneous forest. This only emphasises the importance of site-specific analysis and heterogeneous modelling of the terrain to achieve more accurate prediction of structural loads and service life. 

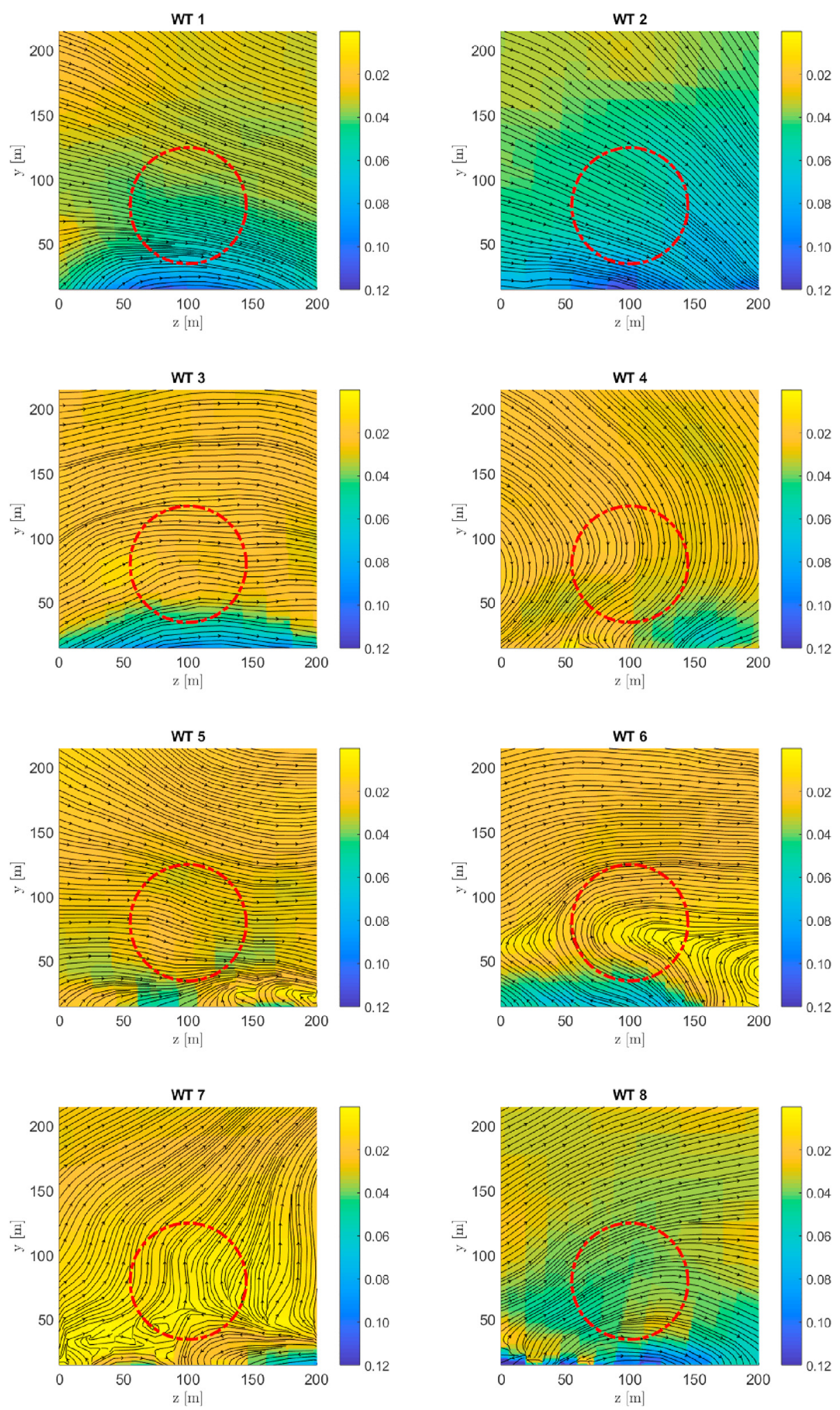

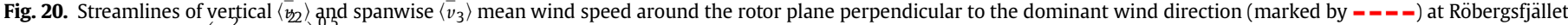
wind farm colored by $\left(\left\langle\bar{v}_{2}\right\rangle+\left\langle\bar{v}_{3}\right\rangle\right)^{0.5} /\left\langle\bar{v}_{1}\right\rangle$. The axial mean wind speed $\left\langle\bar{v}_{1}\right\rangle$ is perpendicular to the rotor plane.

\subsection{Comparison of high-speed shaft cylindrical roller bearing life}

A summary of the high-speed shaft cylindrical bearing lives for the 8 turbines are provided in Table 3. It can be observed here that unlike the structural loads, the bearing life predictions are higher with a homogeneous forest assumption.The primary reason remains the same. Due to the increased turbulence intensity predicted by the homogeneous forest, the turbine spends less time at 


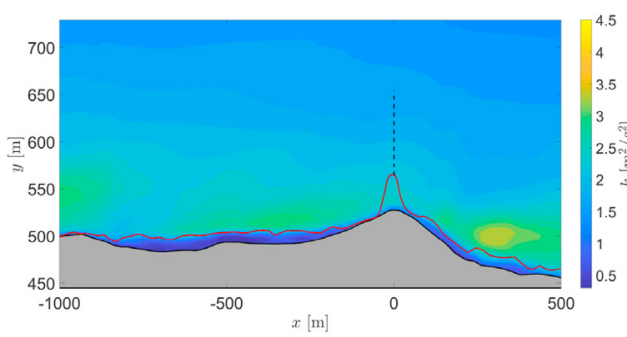

(a)

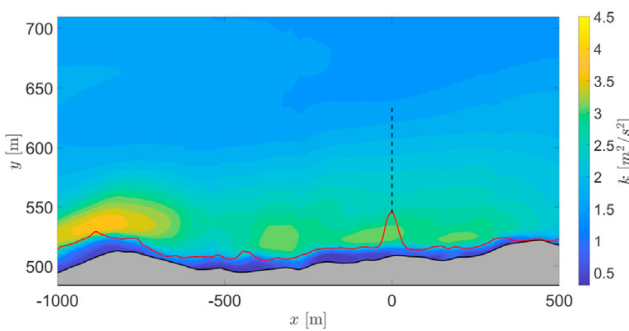

(c)

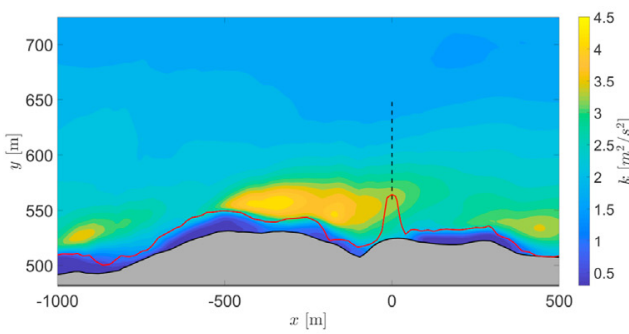

(e)

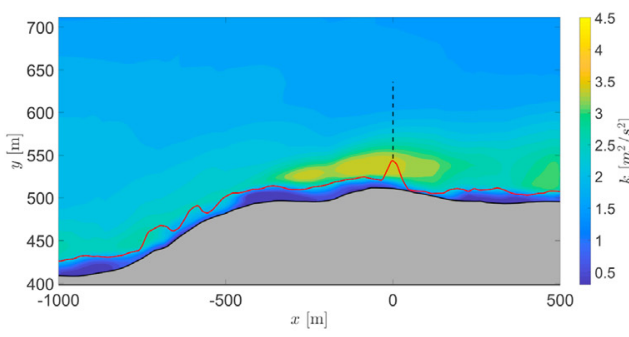

(g)

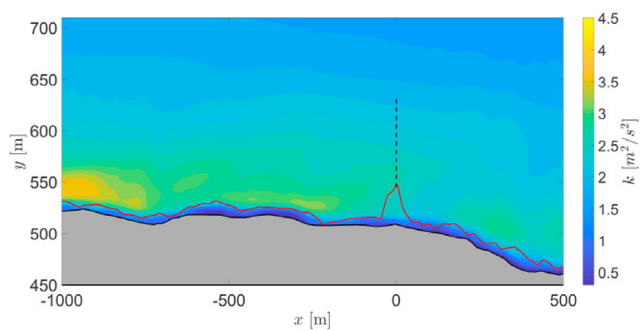

(b)

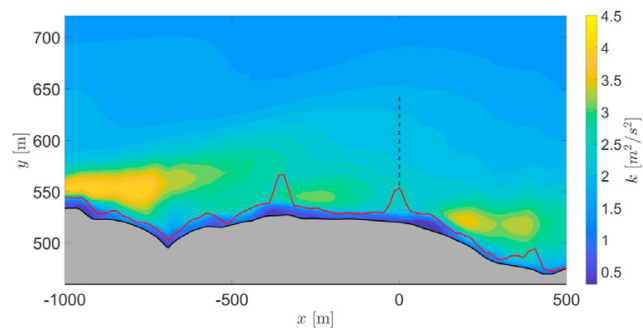

(d)

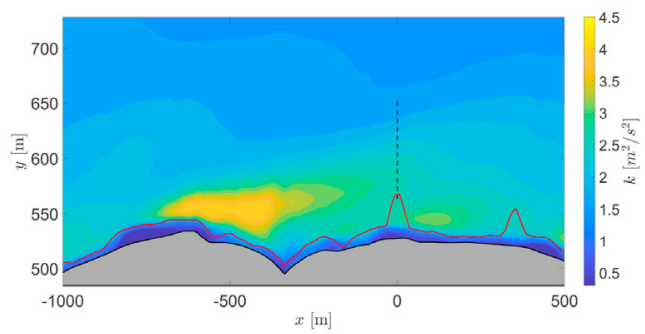

(f)

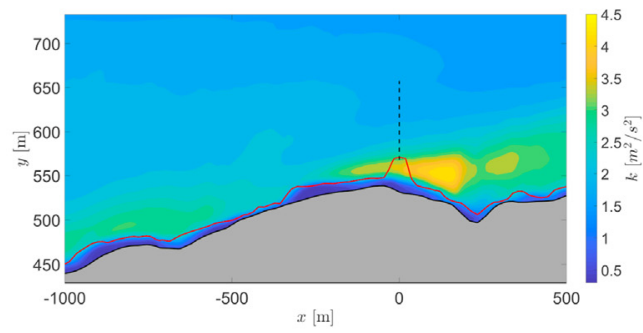

(h)

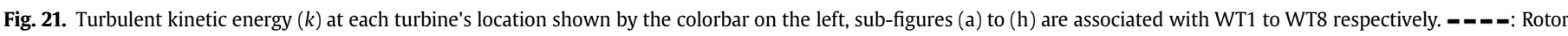

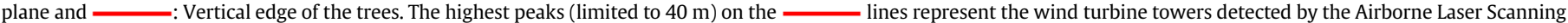
(ALS) measurements as obstruction/vegetation on the terrain.

Table 1

Mean and Standard Deviation (STD) of wind profile properties, over the rotor swept area and at hub height.

\begin{tabular}{|c|c|c|c|c|c|c|c|c|}
\hline \multirow[t]{2}{*}{ Item } & \multirow[t]{2}{*}{ Elevation $[\mathrm{m}]$} & \multicolumn{4}{|l|}{ Mean } & \multicolumn{2}{|l|}{ STD } & \multirow{2}{*}{$\frac{T I_{U_{E q}}}{[-]}$} \\
\hline & & $U_{E q}[\mathrm{~m} / \mathrm{s}]$ & $\left\langle\bar{v}_{1}\right\rangle_{\text {hub }}[\mathrm{m} / \mathrm{s}]$ & $\alpha_{1}[-]$ & $\alpha_{2}[-]$ & $U_{E q}[\mathrm{~m} / \mathrm{s}]$ & $\left\langle\bar{v}_{1}\right\rangle_{\text {hub }}[\mathrm{m} / \mathrm{s}]$ & \\
\hline WT 1 & 527.1 & 10.32 & 10.31 & 0.12 & 0.14 & 1.07 & 1.30 & 0.10 \\
\hline WT 2 & 508.3 & 9.74 & 9.73 & 0.19 & 0.21 & 1.29 & 1.57 & 0.13 \\
\hline WT 3 & 507.8 & 9.61 & 9.66 & 0.28 & 0.23 & 1.11 & 1.44 & 0.12 \\
\hline WT 4 & 519.7 & 9.74 & 9.77 & 0.21 & 0.18 & 1.13 & 1.42 & 0.12 \\
\hline WT 5 & 523.6 & 9.76 & 9.81 & 0.35 & 0.23 & 1.17 & 1.44 & 0.12 \\
\hline WT 6 & 526.6 & 9.79 & 9.81 & 0.23 & 0.20 & 1.15 & 1.45 & 0.12 \\
\hline WT 7 & 510.2 & 10.42 & 10.50 & 0.23 & 0.10 & 1.06 & 1.26 & 0.10 \\
\hline WT 8 & 531.1 & 10.25 & 10.35 & 0.18 & 0.12 & 1.21 & 1.32 & 0.12 \\
\hline
\end{tabular}


Table 2

Comparison of short term damage equivalent loads on wind turbines.

\begin{tabular}{|c|c|c|c|c|c|c|c|c|c|}
\hline \multirow[t]{2}{*}{ Wind Turbine \# } & \multicolumn{3}{|c|}{ Bl1 RootFlpMom DEL [kNm] } & \multicolumn{3}{|c|}{ TwrBsFAMom DEL [kNm] } & \multicolumn{3}{|c|}{ TTYawMom DEL [kNm] } \\
\hline & Het. & Hom. & $\%$ diff. & Het. & Hom. & $\%$ diff. & Het. & Hom. & $\%$ diff. \\
\hline WT 1 & 520 & 546 & 4.8 & 2210 & 2190 & -0.9 & 250 & 313 & 20.1 \\
\hline WT 2 & 511 & 585 & 12.6 & 2320 & 2430 & 4.5 & 290 & 355 & 18.3 \\
\hline WT 3 & 498 & 560 & 11.1 & 2180 & 2320 & 6.0 & 289 & 357 & 19.1 \\
\hline WT 4 & 538 & 522 & -3.1 & 2170 & 2240 & 3.1 & 272 & 343 & 20.7 \\
\hline WT 5 & 610 & 607 & -0.5 & 2180 & 2430 & 10.3 & 335 & 409 & 18.1 \\
\hline WT 6 & 500 & 592 & 15.5 & 2140 & 2490 & 14.1 & 291 & 360 & 19.2 \\
\hline WT 7 & 553 & 559 & 1.1 & 2360 & 2250 & -4.9 & 262 & 303 & 13.5 \\
\hline WT 8 & 544 & 576 & 5.6 & 2260 & 2280 & 0.9 & 249 & 294 & 15.3 \\
\hline
\end{tabular}

Table 3

Comparison of bearing life.

\begin{tabular}{llll}
\hline Wind Turbine \# & \multicolumn{3}{l}{ Bearing life [million revolutions] } \\
\cline { 2 - 4 } & Het. & Hom. & \% diff. \\
\hline WT 1 & 1056 & 1259 & 16.1 \\
WT 2 & 1364 & 1881 & 27.5 \\
WT 3 & 1473 & 1619 & 9.0 \\
WT 4 & 1330 & 1848 & 28.0 \\
WT 5 & 1377 & 1718 & 19.9 \\
WT 6 & 1342 & 1788 & 24.9 \\
WT 7 & 1008 & 1132 & 11.0 \\
WT 8 & 1113 & 1239 & 10.2 \\
\hline
\end{tabular}

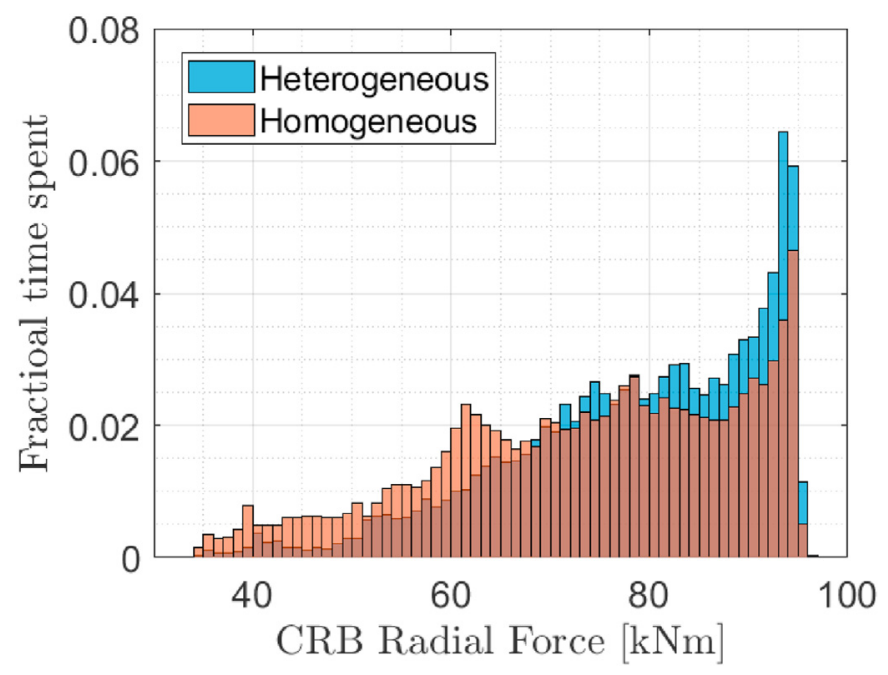

Fig. 22. Histogram of WT 7 HSS-CRB radial bearing force for the heterogeneous and homogeneous forest modelings.

high operating load ranges as can be observed in Fig. 22 for wind turbine 7 . All the other turbines experience similar features hence the radial bearing force of only wind turbine 7 is shown here for demonstrative purposes. As mentioned before, bearings consume their remaining life at a much faster rate during high load operation compared to lower operational loads. Therefore, a modest decrease in time spent at high operating speeds/loads results in a significant increase in remaining bearing life and vise-versa. It must again be noted that these results are site-specific and provide only an indication of the trends. It becomes clear that wrongful estimation of atmospheric turbulence can have a big impact on bearing lives. As we observed, turbine located at places with little vegetation and a more uniform flow will consume their bearing life at a faster rate compared to turbines located in forests. This again emphasises the importance of terrain-specific modelling of the flow in a wind farm.
Comparison between Table 1 and Table 3 reveals that a higher equivalent mean wind speed reduces the life time of the turbine bearings. Moreover, a higher wind shear exponent for the upper sections of the rotor plane $\left(\alpha_{2}\right)$ also has a negative impact on the life time of the turbine bearings. By putting Fig. 20 beside Table 3, it seems that horizontal flow misalignment (yawed flow, as in WT5) has lesser impact than the vertical flow misalignment (inclined flow, as in WT2 and WT4) on the life time of the turbine's bearing knowing that WT2 and WT4 have a lower equivalent mean wind speed than WT5.

\section{Conclusion}

The results show that for a forested hilly terrain turbine-specific structural and drive-train loads can be quite different within a wind farm. Therefore, a single met mast data might not be a real representative for the wind field of entire wind farm.

Variation of inflow variables such as mean wind speed, shear exponent and turbulence intensity at each wind turbine location justifies the need for high-fidelity CFD method - the so-called Large-Eddy Simulation (LES) - to accurately model the airflow inside and over complex terrains and around each wind turbine in a wind farm, despite the expensive computational cost.

The nacelle-mounted anemometer data from SCADA reports a lower mean wind speed for all turbines than LES. However, for a more restrictive set of wind conditions, that better represents neutral atmospheric conditions, the SCADA data are closer to the predicted wind speeds by LES. The more restrictive samples of SCADA data also have a mean value closer to the turbulence intensity (TI) predicted by LES. The difference between the predicted TI by LES and SCADA data is larger for the turbines that are placed in the wake of upstream wind turbine. This shows the necessity of inclusion of wind turbine model (for example, actuator disk or actuator line model) to capture more detailed description of wind field within a wind farm, especially for aeroelastic calculation.

For the wind farm considered in this study, the predicted turbulence intensity under the homogeneous forest assumption is greater than the heterogeneous forest assumption. This leads to higher damage equivalent loads, computed for the blades and tower for the homogeneous forest assumption. Hence, the importance of site-specific analysis and heterogeneous forest modelling of the terrain to achieve more accurate prediction of structural loads and service life is highlighted. On the other hand, the bearing life predictions are higher for the homogeneous forest assumption. This is because the wind turbine, exposed to a higher turbulence intensity, spends less time at high operating ranges resulting in an increase in remaining bearing life. Note here that the bearing life model used is idealized and does not take load transients into account. In addition, it seems that horizontal flow misalignment (yawed flow) has a less negative impact than the vertical flow misalignment (inclined flow) on the life time of the turbine's 
bearing. This claim, however, requires further study and opens up a new research question.

The investigation into the turbine loads presented in this paper shows that there is a considerable difference in the turbine loads and especially the HSS bearing life between the two types of forest assumptions. There is also significant inter-turbine differences in the loads experienced by the turbines in the same wind farm. These differences are attributed to the terrain around the individual turbines that can vary significantly in the same farm. Thus emphasising the fact that proper modeling of the flow considering the heterogeneous terrain is required for better estimation of turbinespecific fatigue life of its components as turbine-specific fatigue life can vary significantly from the average wind turbine fatigue life in a farm.

\section{CRediT authorship contribution statement}

Hamidreza Abedi: Conceptualization, Methodology, Software, Validation, Formal analysis, Data curation, Writing - original draft, Visualization. Saptarshi Sarkar: Conceptualization, Methodology, Software, Validation, Formal analysis, Data curation, Writing original draft, Visualization. Håkan Johansson: Conceptualization, Methodology, Software, Validation, Formal analysis, Data curation, Writing - original draft, Writing - review \& editing, Visualization.

\section{Declaration of competing interest}

The authors declare that they have no known competing financial interests or personal relationships that could have appeared to influence the work reported in this paper.

\section{Acknowledgments}

This project is financed through the Swedish Wind Power Technology Centre (SWPTC). SWPTC is a research centre for the design of wind turbines. The purpose of the centre is to support Swedish industry with knowledge of design techniques as well as maintenance in the field of wind power. The Centre is funded by the Swedish Energy Agency, Chalmers University of Technology as well as academic and industrial partners.

The computations were enabled by resources provided by the Swedish National Infrastructure for Computing (SNIC) at Chalmers Centre for Computational Science and Engineering (C3SE) partially funded by the Swedish Research Council through grant agreement No. 2018-05973.

Software to convert.las data was provided by J, Arnqvist, and is available at https://github.com/johanarnqvist/ALS2PAD.git.

\section{References}

[1] A.S. Monin, The atmospheric boundary layer, Annu. Rev. Fluid Mech. 2 (1) (1970) 225-250.

[2] J.C. Wyngaard, Atmospheric turbulence, Annu. Rev. Fluid Mech. 24 (1) (1992) 205-234.

[3] M.A.C. Teixeira, D.J. Kirshbaum, H. Ólafsson, P.F. Sheridan, I. Stiperski, The atmosphere over mountainous regions, Front. Earth Sci. 4 (2016) 84

[4] Y. Xi, C. Meneveau, Modelling turbulent boundary layer flow over fractal-like multiscale terrain using large-eddy simulations and analytical tools, Philos Trans A Math Phys Eng Sci 375 (2091) (2017) 20160098.

[5] M. Lehner, M. Rotach, Current challenges in understanding and predicting transport and exchange in the atmosphere over mountainous terrain, Atmosphere 9 (7) (2018) 276.

[6] J. Ruel, D. Pin, K. Cooper, Effect of topography on wind behaviour in a complex terrain, Forestry: An International Journal of Forest Research 71 (3) (1998) 261-265.

[7] J. Mann, N. Angelou, J. Arnqvist, D. Callies, E. Cantero, R.C. Arroyo, M. Courtney, J. Cuxart, E. Dellwik, J. Gottschall, S. Ivanell, P. Kühn, G. Lea, J.C. Matos, J.M.L.M. Palma, L. Pauscher, A. Peña, J.S. Rodrigo, S. Söderberg, N. Vasiljevic, C.V. Rodrigues, Complex terrain experiments in the new european wind atlas, Phil. Trans. Math. Phys. Eng. Sci. 375 (2091) (2017) 20160101.

[8] M.K. Liu, M.A. Yocke, Siting of wind turbine generators in complex terrain, J. Energy 4 (1) (1980).

[9] R.J.A.M. Stevens, C. Meneveau, Flow structure and turbulence in wind farms, Annu. Rev. Fluid Mech. 49 (1) (2017) 311-339.

[10] N. Wood, Wind flow over complex terrain: a historical perspective and the prospect for large-eddy modelling, Boundary-Layer Meteorol. 96 (1) (2000) $11-32$.

[11] P.S. Jackson, J.C.R. Hunt, Turbulent wind flow over a low hill, Q. J. R. Meteorol. Soc. 101 (430) (1975) 929-955.

[12] P.J. Mason, R.I. Sykes, Flow over an isolated hill of moderate slope, Q. J. R. Meteorol. Soc. 105 (444) (1979) 383-395.

[13] P.J. Mason, J.C. King, Measurements and predictions of flow and turbulence over an isolated hill of moderate slope, Q. J. R. Meteorol. Soc. 111 (468) (1985) 617-640.

[14] J. Sanz Rodrigo, R.A. Chávez Arroyo, P. Moriarty, M. Churchfield, B. Kosović P.E. Réthoré, K.S. Hansen, A. Hahmann, J.D. Mirocha, D. Rife, Mesoscale to microscale wind farm flow modeling and evaluation, WIREs Energy and Environment 6 (2) (2017) e214.

[15] R.E. Britter, J.C.R. Hunt, K.J. Richards, Air flow over a two-dimensional hill: studies of velocity speed-up, roughness effects and turbulence, Wind Energy 107 (451) (1981) 91-110.

[16] R.L. Simpson, Turbulent boundary-layer separation, Annu. Rev. Fluid Mech. 21 (1) (1989) 205-232.

[17] L. Davidson, Fluid Mechanics, Turbulent Flow and Turbulence Modeling, Lecture Notes; Department of Mechanics and Maritime Sciences, Division of Fluid Dynamics, Chalmers University of Technology, 2020.

[18] S. Feng, X. Zheng, R. Hu, P. Wang, Large eddy simulation of high-Reynoldsnumber atmospheric boundary layer flow with improved near-wall correction, Boundary-Layer Meteorol. 41 (2020) 33-35.

[19] H.W. Detering, D. Etling, Application of the e- $\epsilon$ turbulence model to the atmospheric boundary layer, Boundary-Layer Meteorol. 33 (2) (1985) $113-133$.

[20] O.Zeman, N.O. Jensen, Modification of turbulence characteristics in flow over hills, Q. J. R. Meteorol. Soc. 113 (475) (1987) 55-80.

[21] D.D. Apsley, I.P. Castro, A limited-length-scale k- $\in$ model for the neutral and stably-stratified atmospheric boundary layer, Boundary-Layer Meteorol. 83 (1997) 75-98.

[22] D. Xu, P.A. Taylor, An E- $-\varepsilon-1$ turbulence closure scheme for planetary boundary-layer models: the neutrally stratified case, Boundary-Layer Meteorol. 84 (2) (1997) 247-266.

[23] J. O'Sullivan, Modelling Wind Flow over Complex Terrain, PhD thesis, University of Auckland, New Zealand, 2012.

[24] S. Dupont, Y. Brunet, J.J. Finnigan, Large-eddy simulation of turbulent flow over a forested hill: validation and coherent structure identification, Q. J. R. Meteorol. Soc. 134 (636) (2008) 1911-1929.

[25] A. El Kasmi, C. Masson, Turbulence modeling of atmospheric boundary layer flow over complex terrain: a comparison of models at wind tunnel and full scale, Wind Energy 13 (8) (2010) 689-704.

[26] S. Shamsoddin, F. Porté-Agel, Large-Eddy simulation of atmospheric boundary-layer flow through a wind farm sited on topography, BoundaryLayer Meteorol. 163 (2017) 1-17.

[27] M. Cindori, I. Džijan, F. Juretić, H. Kozmar, The atmospheric boundary layer above generic hills: computational model of a unidirectional body forcedriven flow, Boundary-Layer Meteorol. 176 (2) (2020) 159-196.

[28] G.T. Bitsuamlak, T. Stathopoulos, C. Bédard, Numerical evaluation of wind flow over complex terrain: Review, J. Aero. Eng. 17 (4) (2004) 135-145.

[29] R.J. Barthelmie, E.S. Politis, J.M. Prospathopoulos, S.T. Frandsen, K. Rados, O. Rathmann, K.S. Hansen, W. Schlez, D. Cabezon, J.D.A. Phillips, A. Neubert, S. Pijl, J.G. Schepers, Flow and Wakes in Large Wind Farms in Complex Terrain and Offshore, European Wind Energy Conference, Brussels, Belgium, 2008.

[30] P. Brodeur, C. Masson, Numerical site calibration over complex terrain, J. Sol. Energy Eng. 130 (3) (2008)

[31] S.J. Wakes, T. Maegli, K.J. Dickinson, M.J. Hilton, Numerical modelling of wind flow over a complex topography, Environ. Model. Software 25 (2) (2010) 237-247.

[32] E. Berge, A.R. Gravdahl, J. Schelling, L. Tallhaug, O. Undheim, Wind in Complex Terrain . A Comparison of WAsP and Two CFD-Models, Proceedings EWEC, Athens, Greece, 2006.

[33] D.C. Martínez, K.S. Hansen, R.J. Barthelmie, Analysis and Validation of Cfd Wind Farm Models in Complex Terrain. Effects Induced by Topography and Wind Turbines, 2010.

[34] E.S. Politis, J. Prospathopoulos, D. Cabezon, K.S. Hansen, P.K. Chaviaropoulos, R.J. Barthelmie, Modeling wake effects in large wind farms in complex terrain: the problem, the methods and the issues, Wind Energy 15 (1) (2012) $161-182$.

[35] L. Li, P.W. Chan, L. Zhang, F. Hu, Numerical simulation of a lee wave case over three-dimensional mountainous terrain under strong wind condition, Adv. Meteorol. 2013 (2013), https://doi.org/10.1155/2013/304321.

[36] J.S.R. R Chávez Arroyo, P. Gankarski, Modelling of atmospheric boundarylayer flow in complex terrain with different forest parameterizations, J. Phys. Conf. 524 (2014), 012119.

[37] B. Blocken, A. van der Hout, J. Dekker, O. Weiler, CFD simulation of wind flow 
over natural complex terrain: case study with validation by field measurements for Ria de Ferrol, Galicia, Spain, J. Wind Eng. Ind. Aerod. 147 (2015) 43-57.

[38] B.W. Yan, Q.S. Li, Y.C. He, P.W. Chan, RANS simulation of neutral atmospheric boundary layer flows over complex terrain by proper imposition of boundary conditions and modification on the k-e model, Environ. Fluid Mech. 16 (2016) $1-23$.

[39] S. Ivanell, J. Arnqvist, M. Avila, D. Cavar, R.A. Chavez-Arroyo, H. OlivaresEspinosa, C. Peralta, J. Adib, B. Witha, Micro-scale model comparison (benchmark) at the moderately complex forested site, Wind Energy Science 3 (2) (2018) 929-946.

[40] P.A. Taylor, H.W. Teunissen, The Askervein hill project: overview and background data, Boundary-Layer Meteorol. 39 (1) (1987) 15-39.

[41] A. Bechmann, J. Berg, M.S. Courtney, H.E. Jørgensen, J. Mann, N.N. Sørensen, The Bolund Experiment: Overview and Background. Technical Report, RisøR-1658(EN); Risø DTU, National Laboratory for Sustainable Energy, Technical University of Denmark, 2009.

[42] J. Berg, J. Mann, M.S. Courtney, H.E. Jørgensen, P.E. Réthoré, The Bolund experiment, part i: flow over a steep, three-dimensional hill, Boundary-Layer Meteorol. 141 (2) (2011) 219-243.

[43] G.D. Raithby, G.D. Stubley, P.A. Taylor, The Askervein hill project: a finite control volume prediction of three-dimensional flows over the hill, Boundary-Layer Meteorol. 39 (3) (1987) 247-267.

[44] S.L.A. Castro F Palma J, Simulation of the Askervein flow. part 1: Reynolds averaged Navier-Stokes equations(k- $\varepsilon$ turbulence model), Boundary-Layer Meteorol. 107 (3) (2003) 501-530.

[45] K.J. Eidsvik, A system for wind power estimation in mountainous terrain. prediction of Askervein hill data, Wind Energy 8 (2) (2005) 237-249.

[46] O. Undheim, H.I. Andersson, E. Berge, Non-linear, microscale modelling of the flow over Askervein hill, Boundary-Layer Meteorol. 120 (3) (2006) 477-495.

[47] D. Cavar, P.E. Réthoré, A. Bechmann, N.N. Sørensen, B. Martinez, F. Zahle, J. Berg, M.C. Kelly, Comparison of openfoam and ellipsys3d for neutral atmospheric flow over complex terrain, Wind Energy Science 1 (1) (2016) 55-70.

[48] J. Prospathopoulos, E. Politis, P. Chaviaropoulos, Application of a 3d rans solver on the complex hill of Bolund and assessment of the wind flow predictions, J. Wind Eng. Ind. Aerod. 107-108 (2012) 149-159.

[49] P.J. Mason, D.J. Thomson, Stochastic backscatter in large-eddy simulations of boundary layers, J. Fluid Mech. 242 (1992) 51-78

[50] P.P. Sullivan, J.C. McWilliams, C.H. Moeng, A subgrid-scale model for largeeddy simulation of planetary boundary-layer flows, Boundary-Layer Meteorol. 71 (3) (1994) 247-276.

[51] F. Porté-Agel, C. Meneveau, M. Parlange, A scale-dependent dynamic model for large-eddy simulation: application to a neutral atmospheric boundary layer, J. Fluid Mech. 415 (2000) 261-284.

[52] F. Wan, F. Porté-Agel, R. Stoll, Evaluation of dynamic subgrid-scale models in large-eddy simulations of neutral turbulent flow over a two-dimensional sinusoidal hill, Atmos. Environ. 41 (13) (2007) 2719-2728.

[53] A. Brown, J. Hobson, N. Wood, Large-Eddy simulation of neutral turbulent flow over rough sinusoidal ridges, Boundary-Layer Meteorol. 98 (2) (2001) $411-441$.

[54] T. Allen, A. Brown, Large-Eddy simulation of turbulent separated flow over rough hills, Boundary-Layer Meteorol. 102 (2) (2002) 177-198.

[55] T. Tamura, S. Cao, A. Okuno, LES study of turbulent boundary layer over a smooth and a rough 2d hill model, Flow, Turbul. Combust. 79 (4) (2007) 405-432.

[56] S. Cao, T. Wang, Y. Ge, Y. Tamura, Numerical study on turbulent boundary layers over two-dimensional hills-effects of surface roughness and slope, J. Wind Eng. Ind. Aerod. 104-106 (2012) 342-349.

[57] M.J. Churchfield, S. Lee, J. Michalakes, P.J. Moriarty, A numerical study of the effects of atmospheric and wake turbulence on wind turbine dynamics, J. Turbul. 13 (2012) N14.

[58] S.E. Belcher, I.N. Harman, J.J. Finnigan, The wind in the willows: flows in forest canopies in complex terrain, Annu. Rev. Fluid Mech. 44 (1) (2012) 479-504.

[59] X. Yang, F. Sotiropoulos, R.J. Conzemius, J.N. Wachtler, M.B. Strong, Largeeddy simulation of turbulent flow past wind turbines/farms: the virtual wind simulator (vwis), Wind Energy 18 (12) (2015) 2025-2045.

[60] S.P. Breton, J. Sumner, J.N. Sørensen, K.S. Hansen, S. Sarmast, S. Ivanell, A survey of modelling methods for high-fidelity wind farm simulations using large eddy simulation, Phil. Trans. Math. Phys. Eng. Sci. 375 (2091) (2017) 20160097.

[61] A. Silva Lopes, J.M.L.M. Palma, F.A. Castro, Simulation of the Askervein flow. part 2: large-eddy simulations, Boundary-Layer Meteorol. 125 (2007) $85-108$.

[62] F.K. Chow, R.L. Street, Evaluation of turbulence closure models for large-eddy simulation over complex terrain: flow over Askervein hill, J. Appl. Meteorol. Climatol. 48 (5) (2009) 1050-1065.

[63] J.C. Golaz, J.D. Doyle, S. Wang, One-way nested large-eddy simulation over the Askervein hill, J. Adv. Model. Earth Syst. 1 (3) (2009).

[64] A. Bechmann, Large-eddy Simulation of Atmospheric Flow over Complex Terrain, PhD thesis, Denmark Technical University, 2006

[65] A. Bechmann, N.N. Sørensen, J. Berg, J. Mann, P.E. Réthoré, The Bolund experiment, part ii: blind comparison of microscale flow models, Boundary-
Layer Meteorol. 141 (2) (2011) 245-271.

[66] M. Diebold, C. Higgins, J. Fang, A. Bechmann, M. Parlange, Flow over hills: large-eddy simulation of the Bolund case, Boundary-Layer Meteorol. 148 (2013) 177-194.

[67] V. Vuorinen, A. Chaudhari, J.P. Keskinen, Large-eddy simulation in a complex hill terrain enabled by a compact fractional step openfoam ${ }^{\circledR}$ solver, Adv. Eng. Software 79 (2015) 70-80.

[68] A. Chaudhari, Large-Eddy Simulation of Wind Flows over Complex Terrains for Wind Energy Applications, PhD thesis, Lappeenranta University of Technology, Finland, 2014.

[69] A. Chaudhari, A. Hellsten, J. Hämäläinen, Full-scale experimental validation of large-eddy simulation of wind flows over complex terrain: the Bolund hill, Adv. Meteorol. 2016 (2016) 1-14, https://doi.org/10.1155/2016/9232759.

[70] B. Conan, A. Chaudhari, S. Aubrun, J. van Beeck, J. Hämäläinen, A. Hellsten, Experimental and numerical modelling of flow over complex terrain: the Bolund hill, Boundary-Layer Meteorol. 158 (2) (2016) 183-208.

[71] Y. Ma, H. Liu, Large-Eddy simulations of atmospheric flows over complex terrain using the immersed-boundary method in the weather research and forecasting model, Boundary-Layer Meteorol. 421 (3) (2017) 421-445.

[72] A. Maurizi, J. Palma, F. Castro, Numerical simulation of the atmospheric flow in a mountainous region of the north of Portugal, J. Wind Eng. Ind. Aerod. 74-76 (1998) 219-228.

[73] H.G. Kim, V. Patel, C.M. Lee, Numerical simulation of wind flow over hilly terrain, J. Wind Eng. Ind. Aerod. 87 (1) (2000) 45-60.

[74] F.K. Chow, A.P. Weigel, R.L. Street, M.W. Rotach, M. Xue, High-resolution large-eddy simulations of flow in a steep alpine valley. Part I: methodology, verification, and sensitivity experiments, J. Appl. Meteorol. Climatol. 45 (1) (2006) 63-86.

[75] A.P. Weigel, F.K. Chow, M.W. Rotach, R.L. Street, M. Xue, High-resolution large-eddy simulations of flow in a steep alpine valley. Part II: flow structure and heat budgets, J. Appl. Meteorol. Climatol. 45 (1) (2006) 87-107.

[76] J.C.P.L. da Costa, Atmospheric Flow over Forested and Non-forested Complex Terrain, PhD thesis, Universidade do Porto, Portugal, 2008.

[77] Y. Han, M. Stoellinger, J. Naughton, Large eddy simulation for atmospheric boundary layer flow over flat and complex terrains, J. Phys. Conf. 753 (2016), 032044.

[78] LES study on the turbulent flow fields over complex terrain covered by vegetation canopy, J. Wind Eng. Ind. Aerod. 155 (2016) 60-73.

[79] X. Yang, M. Pakula, F. Sotiropoulos, Large-eddy simulation of a utility-scale wind farm in complex terrain, Appl. Energy 229 (2018) 767-777.

[80] J. Berg, N. Troldborg, N.S.E.G.P, P.P. Sullivan, Modelling of atmospheric boundary-layer flow in complex terrain with different forest parameterizations, J. Phys. Conf. 854 (2017), 012003.

[81] P. Enevoldsen, Onshore wind energy in northern european forests: reviewing the risks, Renew. Sustain. Energy Rev. 60 (2016) 1251-1262.

[82] A two-equation turbulence model for canopy flows, J. Wind Eng. Ind. Aerod. 35 (1990) 201-211.

[83] R.H. Shaw, U. Schumann, Large-eddy simulation of turbulent flow above and within a forest, Boundary-Layer Meteorol. 61 (1992) 47-64.

[84] A. Lopes, J.M.L.M. Palma, J.V. Lopes, Improving a two-equation turbulence model for canopy flows using large-eddy simulation, Boundary-Layer Meteorol. 149 (2) (2013) 231-257.

[85] E. Mueller, W. Mell, A. Simeoni, Large eddy simulation of forest canopy flow for wildland fire modeling, Can. J. For. Res. 44 (12) (2014) 1534-1544.

[86] B. Nebenführ, L. Davidson, Prediction of wind-turbine fatigue loads in forest regions based on turbulent LES inflow fields, Wind Energy 20 (6) (2017) 1003-1015.

[87] B. Nebenführ, L. Davidson, Prediction of wind turbine fatigue loads in forest regions based on turbulent LES inflow fields, J Wind Energy 20 (2017) 1003-1015.

[88] E. Patton, Large-Eddy Simulation of Turbulent Flow above and within a Plant Canopy, PhD thesis, University of California Davis, 1997.

[89] M. Mohr, J. Arnqvist, H. Abedi, H. Alfredsson, M. Baltscheffsky, H. Bergström, I. Carlen, L. Davidson, A. Segalini, S. Söderberg, Wind power in forests ii, Report 499 (2018). Energiforsk; 2018.

[90] E.G. Patton, P.P. Sullivan, K.J. Davis, The influence of a forest canopy on topdown and bottom-up diffusion in the planetary boundary layer, Q. J. R. Meteorol. Soc. 129 (590) (2003) 1415-1434.

[91] J. Arnqvist, J. Freier, E. Dellwik, Robust processing of airborne laser scans to plant area density profiles, Biogeosci. Discuss. 2020 (2020) 1-19.

[92] M. Weiss, F. Baret, G. Smith, I. Jonckheere, P. Coppin, Review of methods for in situ leaf area index (LAI) determination: Part II. Estimation of LAI, errors and sampling, Agric. For. Meteorol. 121 (1) (2004) 37-53.

[93] L.É. Boudreault, A. Bechmann, N.N. Sørensen, A. Sogachev, E. Dellwik, Canopy structure effects on the wind at a complex forested site, J. Phys. Conf. 524 (2014), 012112.

[94] L.É. Boudreault, Reynolds-averaged Navier-Stokes and Large-Eddy Simulation over and inside Inhomogeneous Forests, PhD thesis, Denmark Technical University, 2015.

[95] M. Monsi, T. Saeki, On the factor light in plant communities and its importance for matter production, Ann. Bot. 95 (3) (2005) 549-567.

[96] L. Étienne Boudreault, A. Bechmann, L. Tarvainen, L. Klemedtsson, I. Shendryk, E. Dellwik, A lidar method of canopy structure retrieval for wind modeling of heterogeneous forests, Agric. For. Meteorol. 201 (2015) 86-97.

[97] A.N. Ross, Boundary-layer flow within and above a forest canopy of variable 
density, Q. J. R. Meteorol. Soc. 138 (666) (2012) 1259-1272.

[98] J.M. Jonkman, M.L. Buhl Jr., et al., Fast User's Guide vol. 365, National Renewable Energy Laboratory, Golden, CO, 2005, p. 366.

[99] J. Arnqvist, Software to convert airborne laser scans to plant area density (als2pad). https://github.com/johanarnqvist/ALS2PAD.git, 2020.

[100] IEC 61400-1:2019, Wind Energy Generation Systems - Part 1: Design Requirements. Tech. Rep. 61400-1:2019, International Electrotechnical Commission, 2019.

[101] P. Richards, R. Hoxey, Appropriate boundary conditions for computational wind engineering models using the $\mathrm{k}-\varepsilon$ turbulence model, J. Wind Eng. Ind. Aerod. 46-47 (1993) 145-153.

[102] L. Breuer, K. Eckhardt, H.G. Frede, Plant parameter values for models in temperate climates, Ecol. Model. 169 (2) (2003) 237-293.

[103] R.H. Shaw, G. Den Hartog, H.H. Neumann, Influence of foliar density and thermal stability on profiles of Reynolds stress and turbulence intensity in a deciduous forest, Boundary-Layer Meteorol. 45 (4) (1988) 391-409.

[104] J. Smagorinsky, General circulation experiments with the primitive equations. part I, the basic experiment, Mon. Weather Rev. 91 (3) (1963) 99-164, https://doi.org/10.2514/8.3713.

[105] E.R. Van Driest, On turbulent flow near a wall, J. Aeronaut. Sci. 23 (11) (1956) 1007-1011, https://doi.org/10.2514/8.3713.

[106] E. Balaras, C. Benocci, U. Piomelli, Two-layer approximate boundary conditions for large-eddy simulations, AIAA J. 34 (6) (1996) 1111-1119, https:// doi.org/10.2514/3.13200.

[107] N. Jarrin, S. Benhamadouche, D. Laurence, R. Prosser, A synthetic-eddymethod for generating inflow conditions for large-eddy simulations, Int. J. Heat Fluid Flow 27 (4) (2006) 585-593.

[108] J. O'Sullivan, R. Archer, R. Flay, Consistent boundary conditions for flows within the atmospheric boundary layer, J. Wind Eng. Ind. Aerod. 99 (1) (2011) 65-77.

[109] Vestas Wind Systems A/S, General specification V90-1.8/2.0 MW 50 Hz VCS. http://ventderaison.eu/gembloux/eie_ABO-WIND/Annexes/Annexe_N_1_ Courbe_acoustique_V90.pdf, 2010. (Accessed 23 April 2021).

[110] J. Jonkman, S. Butterfield, W. Musial, G. Scott, Definition of a 5-mw Reference Wind Turbine for Offshore System Development, Tech. Rep., National Renewable Energy Lab.(NREL), Golden, CO (United States), 2009.

[111] K. Thomsen, The Statistical Variation of Wind Turbine Fatigue Loads. No.
1063(EN) in Denmark, Forskningscenter Risø. Risø-R, 1998.

[112] A. Crespo, J. Hernández, S. Frandsen, Survey of modelling methods for wind turbine wakes and wind farms, Wind Energy 2 (1) (1999) 1-24.

[113] G. Hayman, Mlife Theory Manual for Version 1.00, National Renewable Energy Laboratory (NREL), 2012.

[114] E. Artigao, S. Martín-Martínez, A. Honrubia-Escribano, E. Gómez-Lázaro, Wind turbine reliability: a comprehensive review towards effective condition monitoring development, Appl. Energy 228 (2018) 1569-1583.

[115] S. Sheng, Wind Turbine Gearbox Reliability Database, Condition Monitoring and Operation and Maintenance Research Update. Tech. Rep, National Renewable Energy Lab.(NREL), Golden, CO (United States), 2016.

[116] SKF, SKF Bearing Maintenance Handbook, 2011. https://www.skf.com binaries/pub12/Images/0901d1968013be94-SKF-bearing-maintenancehandbook-10001_1-EN(1)_tcm_12-463040.pdf. (Accessed 23 April 2021).

[117] IEC 61400-12-1:2017, Wind Energy Generation Systems - Part 12-1: Power Performance Measurements of Electricity Producing Wind Turbines. Tech. Rep. 61400-12-1:2017, International Electrotechnical Commission, 2017.

[118] N. Kelley, B. Smith, K. Smith, G. Randall, D. Malcolm, Evaluation of Wind Shear Patterns at Midwest Wind Energy Facilities. Technical Report, NREL CP-500-32492, National Renewable Energy Laboratory, USA, 2002.

[119] J.S. Irwin, A theoretical variation of the wind profile power-law exponent as a function of surface roughness and stability, Atmos. Environ. 13 (1) (1967) 191-194, 1979.

[120] M. Kelly, G. Larsen, N.K. Dimitrov, A. Natarajan, Probabilistic meteorological characterization for turbine loads, J. Phys. Conf. 524 (2014), 012076.

[121] M. Ray, A. Rogers, J. McGowan, Analysis of Wind Shear Models and Trends in Different Terrains, University of Massachusetts, Department of Mechanical and Industrial Engineering, Renewable Energy Research Laboratory, 2006.

[122] G. Geernaert, Surface Layer, encyclopedia of atmospheric sciences, 2003.

[123] S. Asadi, H. Johansson, Multibody dynamic modelling of a direct wind turbine drive train, Wind Eng. 44 (5) (2020) 519-547.

[124] B. Yang, A. Morse, R. Shaw, K. Paw U, Large-eddy simulation of turbulent flow across a forest edge. part ii: momentum and turbulent kinetic energy budgets, Boundary-Layer Meteorol. 121 (3) (2006) 433-457.

[125] F. Kanani, K. Träumner, B. Ruck, S. Raasch, What determines the differences found in forest edge flow between physical models and atmospheric measurements? an LES study, Meteorol. Z. 23 (1) (2014) 33-49. 